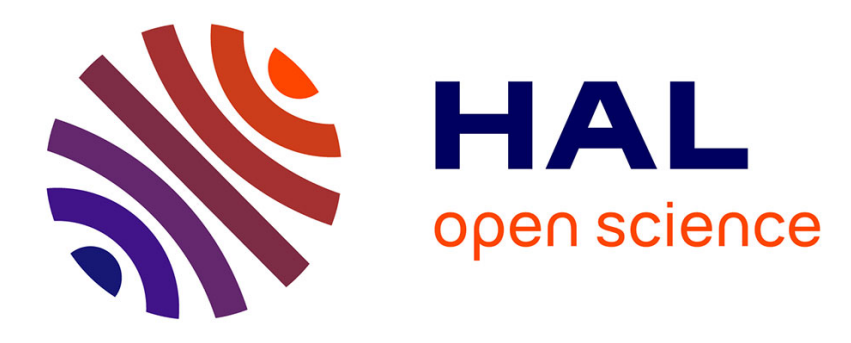

\title{
Equity justifications for universal service obligations
} Jean-Christophe Poudou, Michel Roland

\section{To cite this version:}

Jean-Christophe Poudou, Michel Roland. Equity justifications for universal service obligations. International Journal of Industrial Organization, 2017, 52, pp.63 - 95. 10.1016/j.ijindorg.2017.01.007 . hal-01810301

\section{HAL Id: hal-01810301 \\ https://hal.umontpellier.fr/hal-01810301}

Submitted on 6 Dec 2019

HAL is a multi-disciplinary open access archive for the deposit and dissemination of scientific research documents, whether they are published or not. The documents may come from teaching and research institutions in France or abroad, or from public or private research centers.
L'archive ouverte pluridisciplinaire HAL, est destinée au dépôt et à la diffusion de documents scientifiques de niveau recherche, publiés ou non, émanant des établissements d'enseignement et de recherche français ou étrangers, des laboratoires publics ou privés. 


\title{
Equity Justifications for Universal Service Obligations
}

\author{
Jean-Christophe Poudou* and Michel Roland ${ }^{\dagger \ddagger}$
}

February 9, 2017

\begin{abstract}
Equity is often invoked as a possible justification for the imposition of universal service obligations (USOs). However, no previous analysis supports a formal link between equity and USO. In this paper, we describe the extent to which the imposition of USOs in oligopolistic network industries can meet the objectives of an inequality-averse regulator. We show that USOs can be used for equity purposes provided that the regulator is able to control the competitive structure of the industry. We also show that the uniform pricing constraint, which is an obligation to offer the same price conditions to all consumers, is welfare-enhancing but rather surprisingly, it does not necessarily improve equity.
\end{abstract}

Keywords: equity, coverage and price constraints, regulation, universal service obligations.

JEL: L51, D63, K23

${ }^{*}$ LAMETA, Université de Montpellier, Espace Richter, av. Raymond Dugrand, CS 79606, 34960 Montpellier cedex 2, France. email: jean-christophe.poudou@umontpellier.fr

${ }^{\dagger}$ Corresponding author: CREATE, Département d'économique, Université Laval, 1025, avenue des SciencesHumaines, Québec, QC, G1V 0A6, Canada. email: Michel.Roland@ecn.ulaval.ca.

${ }^{\ddagger}$ We thank participants at the $55^{t h}$ Congress of the Société canadienne de science économique, the $32^{\text {th }}$ Journées de microéconomie appliquée, the $50^{\text {th }}$ Annual Conference of the Canadian Economics Association and the $32^{\text {nd }}$ Annual Meeting of the European Economic Association for helpful comments on earlier versions of this paper. All of the errors or omissions are our own. 


\section{Introduction}

Universal service obligations (USOs) are common in network industries such as telecommunications, electricity distribution, or postal services, where their objective is to ensure the greatest access to a service that is deemed essential. However, the economic rationale behind this objective is not clear and it is still a matter of debate. Cremer et al. [10] argued that the most "compelling theoretical justification" for USOs is their relative efficiency as a redistributive policy. ${ }^{1}$ This justification comes from the uniform pricing constraint which is generally included in USOs: uniform pricing is a redistribution instrument through price that has the potential to be optimal in a second-best world when "policy makers do not have the necessary information to implement (potentially) more efficient policies like direct transfers". ${ }^{2}$ Although convincing, this argument is based on a case where the regulator has full control of the price in a natural monopoly industry. In general, the equity justification for USOs, which is often considered to be self-evident by policy makers, is not grounded on firm theoretical grounds in a context where there is competition.

In this paper, we describe the extent to which USOs in oligopolistic network industries can meet the objectives of an inequality-averse regulator. We use a model where identical consumers are distributed on a continuum of markets, which differ in terms of their fixed connection costs to the network. ${ }^{3}$ Two firms can potentially enter each market. Following Cremer et al. [11] and Valletti et al. [24], we consider USOs as constraints imposed on the activities of firms. Three such constraints are analyzed: a coverage constraint (CC), which obliges one of the firms to serve a given segment of the markets, a license constraint (LC), which controls competition by determining whether there are one or two firms in each market, and a uniform pricing (UP) constraint, which forces firms to offer the good at the same price in all the markets that they serve. The CC can be considered to be the basic component of a USO because it corresponds to the idea of making the service available to the largest possible group of consumers. The UP constraint is often considered complementary because, as argued by Cremer et al. [11], it is meaningless for high-cost consumers to formally have access to a service if the firms are able to price them out of the market. ${ }^{4}$ For

\footnotetext{
${ }^{1}$ Two types of redistribution are highlighted: from low-cost to high-cost consumers and from high-income to low-income consumers.

${ }^{2}$ Cremer et al. [10], p. 25.

${ }^{3}$ As mentioned in Choné et al. [8], this is meant to represent the "geographical component" of USOs, i.e., the component that addresses the redistribution from low-cost to high-cost consumers, as opposed to the "social component", which addresses the redistribution from high-income to low-income consumers. This geographical component is prevalent in network industries.

${ }^{4}$ This argument implicitly assumes that firms can commit to charge high price in high-cost areas before deployment of the network, so demand is nil and the network is not built. Such behavior is not possible in our model, as the
} 
Cremer et al. [10], it is also the prime source of the equity justification for the USO. The LC is also complementary to the CC because it protects the firm that is subject to the latter (the USO provider) from unfair competition: it can either force entry into high-cost markets in order to avoid cream-skimming, or restrict entry to ensure the profitability of the USO provider. The analysis of the LC has been relatively neglected in previous studies of USOs. Indeed, to the best of our knowledge, it has only been analyzed by Crew and Kleindorfer [12] and by Poudou and Roland [23] in terms of efficiency, whereas it has never been considered for equity purposes.

In order to highlight an eventual redistributive function for USOs, in our main analysis, we use assumptions that facilitate its emergence. First, we assume that the regulator can make lump-sum transfers between firms, thereby maximizing social welfare under a single industry profit constraint, rather than under multiple firms' participation constraints. This allows for more redistribution by softening the constraints facing the regulator. Second, we forbid any transfer to consumers, either originating from the firms' profit or from other external sources, such as government subsidies. This means that there is no alternative to USOs for reaching an equity target. We relax the assumption on lump-sum transfers between firms in Section 6, and we find that the qualitative results are not modified by this relaxation, although the redistributive capacity of USOs are unsurprisingly attenuated. ${ }^{5}$

In our analysis, we first study USOs without the UP constraint. We notice that a basic USO with only a CC improves welfare compared to a unregulated market but that the optimal market coverage is independent of the regulator's aversion to inequality because it is determined solely by the industry profit constraint. To make the regulator able to consider a trade-off between efficiency and equity, it is then necessary to join a LC to the USO: restricting entry improves the industry profitability and thus allows for increased market coverage. Accordingly, under CC+LC, the greater is the regulator's aversion to inequality, the lesser is allowed competition and the greater is the coverage imposed to the universal service provider. The upshot is that the regulator must have control on the competitive level of the industry in order to reach specific equity objectives.

We then introduce the UP constraint. A priori, this should levy the price differential obstacle to equality. In fact, we show that the addition of UP to the CC and to the LC effectively increases social welfare, but surprisingly, this increase is allowed through the relaxation of the profit constraint, rather than through the equalization of the different market prices. Furthermore, even though the

network will be deployed before firms choose quantity and price. Here, we focus on the analysis of the equity rationale attributed to uniform pricing.

${ }^{5}$ Relaxing the assumption on the absence of transfers to consumers allows a multitude of transfer mechanisms to be considered, so that their analysis is beyond the scope of the present study. Intuitively, the presence of alternative redistribution instruments should again reduce the role of USOs for equity purposes. 
increase in social welfare can sometimes be explained partially by a reduction of inequality, this is not necessarily the case. It is possible that UP creates efficiency gains that are sufficiently strong to justify a less equitable outcome, even if the regulator's has a relatively strong aversion to inequality. We thus find that there is an efficiency rationale of imposing a UP constraint but, in contrast to conventional wisdom, no general claim can be made on its impact on equity. Again, we note that the social welfare improvement of UP is conditional on imposing a LC.

The efficiency property of UP under USOs has been the focus of Poudou and Roland [23]. Their work can be related to the literature on the impacts of third-degree price discrimination on welfare as they compare the sum of consumer and producer surplus under uniform pricing (i.e. with no price discrimination) and under price discrimination. In their model, despite identical aggregate demands and marginal costs across different markets, differential pricing occurs because one firm operates in both monopolistic and duopolistic markets, thus facing demands with different elasticities as in the "classic" third-degree price-discrimination. ${ }^{6}$ They show that, for given coverages, UP improves allocative efficiency by (i) equalizing marginal willingness to pay among the consumers and (ii) making the price paid on average closer to marginal cost. However, as in Valletti et al. [24], the given coverages assumption does not hold at equilibrium ${ }^{7}$ as the imposition of UP creates strategic links among markets that make firms modify their coverages. Controlling market coverages through $\mathrm{CC}$ and LC then allows the regulator to take into account these strategic links, so that UP in a well-crafted USO increases the sum of consumers' and producers' surplus.

This efficiency result is however mute on equity properties of UP. Our main contribution is to use this framework to provide a formal analysis that links the working of USOs to equity in a competitive environment. Most economic models of USOs assume that their imposition is exogenous before proceeding to efficiency comparisons of different implementations of a universal service. ${ }^{8}$ To the best of our knowledge, only Cremer et al. [10] explicitly state the role of USOs as a secondbest redistributive device with the help of a model. However, they assume that the industry is monopolistic and that the price is fully controlled by the regulator, thus ignoring how strategic interactions of firms in a oligopolistic industry modify the impact of a USO.

\footnotetext{
${ }^{6}$ This is in contrast to Chen and Schwarz [7] who treat the case of differential pricing in face of different marginal costs. In such a case, imposition of uniform pricing is source of allocation inefficiency, a case excluded in Poudou and Roland [23] as the focus is put on different fixed costs of entry.

${ }^{7}$ The impact of price discrimination (or, for that matter, uniform pricing) on entry has been studied for different market setups. See JorgePires [19].

${ }^{8}$ For example, see Anton et al. [3], Bourguignon and Ferrando [5], Calzada [6], Choné et al. [8], [9], Foros and Kind [13], Gautier and Minuzo [14], Gautier and Paolini [15], Gautier and Wauthy [16], [17], and Jaag [18].
} 
In the following section, we describe our model of the network industry, the regulator's preferences, and the USO constraints analyzed. Section 3 presents the benchmark scenarios used to evaluate the performance of USOs. Section 4 analyzes the properties of USOs without UP, first with the basic CC component and then with both the CC and the LC. Section 5 then introduces the UP constraint. In Section 6, we analyze the impact of restricting the transfers between firms. In the conclusion, we discuss possible extensions of our model.

\section{Model}

Two firms can potentially supply a homogeneous good on a continuum of locations $\theta \in[0,1]$, which are distributed in the territory according to the density $f(\theta)=F^{\prime}(\theta)$, where $F(\theta)$ is $\log$ concave. At each location, there is a mass 1 of identical consumers so that $F(0)=0$ and $F(1)=1$. Consumers are represented by a twice differentiable demand function $D(p)$, where $p$ is the price of the good. The consumers' surplus is then given by $v(p)=\int_{p} D(x) d x$. The net consumer's surplus for an agent located in $\theta$ is denoted by $V(\theta)=v(p(\theta))+t(\theta)$ if the good is actually consumed and by $V(\theta)=\epsilon+t(\theta)$ if not, where $t(\theta)$ is a lump-sum transfer, ${ }^{9}$ and $\epsilon$ is the utility associated with a (poor) substitute that is set arbitrarily close to zero. ${ }^{10}$ For each firm, the fixed cost of entering location $\theta$ is $k \theta$, so the locations are ranked in increasing order of cost. Firms also have the same marginal cost of production $c$, which is assumed to be constant and normalized to zero (i.e., $c=0$ ). The operating profit obtained by a firm serving location $\theta$ at price $p$ is denoted by $r(p)=p D(p)$ with $r(0)=0$, so that the profit at location $\theta$ is $\pi(p, \theta)=r(p)-k \theta$. When both firms are present at a given location, they compete $\grave{a}$ la Cournot.

We let $\varepsilon(p) \equiv-\frac{D^{\prime}(p)}{D(p)} p$ be the elasticity of demand and $\Omega(p) \equiv \frac{D^{\prime \prime}(p)}{D^{\prime}(p)} p$ be the elasticity of the slope of the demand function. In order to ensure the existence of the Cournot equilibrium, we assume that the elasticity of the slope of the demand function is greater than or equal to -1 . It is then straightforward to show that $\varepsilon^{\prime}(p) \geq 0 .{ }^{11}$ We also assume that the demand function is such that $\Omega^{\prime}(p) \leq 0 .{ }^{12}$ This means that demand becomes more concave as the price increases. As explained by Aguirre et al. [1], a price change has less impact on the sum of consumer surplus and producer surplus when the demand function is more concave.

\footnotetext{
${ }^{9}$ The regulator will not be able to make such transfers, but they are possible in our first-best benchmark.

${ }^{10} \mathrm{~A}$ strictly positive $\epsilon$ allows for a well-defined welfare function even when the regulator has a strong aversion to inequality (e.g., a Rawlsian regulator).

${ }^{11}$ See Poudou and Roland [23] for a formal proof.

${ }^{12}$ This condition holds for a large class of demand functions, such as strictly concave, linear, and exponential functions.
} 
A regulator has the mandate to ensure that the good is allocated following three equity principles or axioms: (i) independence of unconcerned agents, which states that if consumers at location $\theta$ obtain the same surplus under two different allocations, then $V(\theta)$ has no impact on the comparison of these two allocations in terms of social welfare; (ii) the Pigou-Dalton transfer principle, which states that social welfare should increase if the utility gap between two agents is reduced while the aggregate utility of both agents is maintained; and (iii) independence of common scale, which states that a rescaling of profiles $\{V(\theta)\}$ does not affect the social ordering of the profiles.

As shown by Moulin [21], the following set of functions satisfies (up to a multiplicative constant) these three properties simultaneously: ${ }^{13}$

$$
\left\{W_{\rho} \mid W_{\rho}=\left[\int_{0}^{1} V(\theta)^{1-\rho} f(\theta) d \theta\right]^{\frac{1}{1-\rho}}, \rho \geq 0 \text { and } \rho \neq 1\right\},
$$

where each function belonging to the set is parametrized by $\rho$. An element $W_{\rho}$ is a weighted mean of utilities of order $1-\rho,{ }^{14}$ which is a continuous-sum equivalent to the CES function, with $\frac{1}{\rho}$ as the elasticity of substitution. When $\rho=0, W_{\rho}$ is the standard utilitarian function; when $\rho \rightarrow \infty$, we have the leximin case. Parameter $\rho$ then represents a coefficient of inequality aversion. This can be seen by writing $W_{\rho}$ as $W_{\rho}=\left[\frac{1}{1-\rho} \int_{0}^{1} \phi(V(\theta)) f(\theta) d \theta\right]^{\frac{1}{1-\rho}}$ where $\phi(V) \equiv(1-\rho) V^{1-\rho}$ : then $\phi$ is concave and the elasticity of its slope, given by $-V \frac{\phi^{\prime \prime}}{\phi^{\prime}}=\rho$, represents the aversion to inequality. ${ }^{15} \mathrm{In}$ order to simplify the presentation of problems and their first-order conditions (FOCs), we consider that the objective function is $\int_{0}^{1} \phi(V) d F=(1-\rho)\left(W_{\rho}\right)^{1-\rho}$, which is an increasing transformation of $W_{\rho}$.

Thus, even though the regulator necessarily adheres to the above three equity principles, it can do so with different valuations of the trade-off between efficiency and equity, reflecting its aversion to inequality. This goes from no aversion at all for the utilitarian regulator, so that efficiency is the sole preoccupation, to total intolerance to inequality for the leximin regulator, so that the objectives of equity and efficiency are put in hierarchical order, with the priority given to equity. For intermediate cases $(0<\rho<\infty)$, the greater is $\rho$, the less inclined is the regulator to substitute the utility of one person for another for the sake of efficiency and thus, the more intense is the promotion of equity. For such intermediate values, we distinguish the part of $W_{\rho}$ that is attributable to aversion to inequality from the part that is attributable to efficiency by using the Atkinson inequality index $A_{\rho} \equiv 1-W_{\rho} / \int_{0}^{1} V(\theta) f(\theta) d \theta$.

\footnotetext{
${ }^{13}$ If we add $W_{1} \equiv \lim _{\rho \rightarrow 1} W_{\rho}=\exp \left[\int_{0}^{1} \ln (V(\theta)) f(\theta) d \theta\right]$, then the set becomes the only set of functions that satisfies the three properties.

${ }^{14}$ See Mitrinovic [20]. Note that we later use the fact that such a function is decreasing in $\rho$.

${ }^{15}$ Note that $\phi$ has the useful property that the degree of aversion to inequality is constant.
} 
The only instrument that the regulator has to hand is the imposition of USOs. More precisely, the regulator can impose constraints on the locations that firms can serve and on the prices that they can charge. Thus, regulation comprises one or a combination of the following components.

CC - Coverage Constraint: An obligation for one of the firms (designated as the "incumbent" in the following) to serve all locations $\theta \in\left[0, \theta_{m}\right]$. This obligation can be partly or fully compensated by a lump-sum transfer from the other firm (designated as "the entrant"). This constraint constitutes the backbone of USOs in practice. When $\theta_{m}=1$, this corresponds to the "ubiquity constraint".

LC - License Constraint: A mandate given to the entrant to serve all locations $\theta \in\left[0, \theta_{d}\right]$, and only these locations. By construction, $\theta_{d} \leq \theta_{m}$. This constraint can be imposed either to protect the incumbent from competition in high-cost markets or to expand competition in the face of creamskimming. In practice, the first case is referred to as the incumbent's "reserved area", whereas the second case corresponds more generally to conditions included in operating licenses.

UP - Uniform Pricing Constraint: An obligation for the incumbent to supply, in markets it serves, quantities such that prices are equal across these markets.

Finally, the regulator has the capacity to make lump-sum transfers between firms, so that its choices are subject to an industry profit constraint rather than individual firm's participation constraints. In practice, transfers between firms can be made by establishing a "USO fund", which serves to compensate the universal service provider for the cost of USOs and is financed by the industry consumers or producers. Allowing such transfers to be lump sums provides the "best chance" for the USO to have a role as a redistributive instrument. Similarly, we consider that no transfers are possible to the consumers, either from firms or from external sources such as taxation or subsidization from government. Thus, we eliminate any substitute for USOs in terms of transfers, which further enhances the eventual redistributive role of the USOs.

\section{Benchmarks}

To evaluate the performance of USOs in terms of efficiency and equity, we compare the results obtained under various combinations of USO constraints with the polar cases of the first-best allocation, which represents the ultimate goal of the regulator, and the unregulated allocation, which defines the basic industry performance that the regulator tries to improve. 


\subsection{First-Best}

In the first-best benchmark, we assume that the regulator has full control of the industry and that it can make lump-sum positive or negative transfers to consumers from the firms' profits. Thus, it maximizes the value of function (1) subject to the transfer constraint: $\int_{0}^{1} t(\theta) f(\theta) d \theta \leq$ $F\left(\theta_{m}\right) r(p)-k H\left(\theta_{m}\right)$, where $t(\theta)$ represents the lump-sum transfer to location $\theta$ and $H\left(\theta_{m}\right)=$ $\int_{0}^{\theta_{m}} \theta f(\theta) d \theta$. This requires the satisfaction of productive, allocative, and consumer participation efficiency as well as full equity whenever $\rho>0$. Considering each of these requirements in turn, the solution can be characterized as follows.

- Productive efficiency: since the industry is a natural monopoly, only one firm is exploited; in other words, $\theta_{d}=0$.

- Allocative efficiency: the price is set at marginal cost, which in our case means that the price is 0 .

- Participation efficiency: the firm's coverage is given by:

$$
\theta_{m}^{*} \equiv \min \left\{\frac{v(0)}{k}, 1\right\}
$$

so the marginal coverage cost never exceeds its marginal value.

- Equity: if $\rho>0$, transfers are made to equalize the surplus across locations while compensating the firm for its deficit, so that each consumer obtains: ${ }^{16}$

$$
F\left(\theta_{m}^{*}\right) v(0)-k H\left(\theta_{m}^{*}\right)
$$

Note that, whenever $\rho>0$, the first-best allocation is independent of aversion to inequality: the possibility of lump-sum transfers allows to reach jointly efficiency and equity. ${ }^{17}$ USO can thus be thought as a second-best transfer technology and we try to assess its relative performance in terms of efficiency and equity.

\footnotetext{
${ }^{16}$ So the transfers are given by:

$$
t(\theta)= \begin{cases}-\left(1-F\left(\theta_{m}\right)\right) v(0)-k H\left(\theta_{m}\right)<0 & \text { if } \theta \leq \theta_{m}^{*} \\ F\left(\theta_{m}\right) v(0)-k H\left(\theta_{m}\right)>0 & \text { if } \theta>\theta_{m}^{*}\end{cases}
$$

${ }^{17}$ If the regulator is utilitarist $(\rho=0)$, then any feasible transfer (or no transfer) is optimal as the regulator does not care about equity.
} 


\section{$3.2 \quad$ Unregulated Market (UM)}

In the unregulated market (UM) benchmark, we assume that the regulator cannot intervene in markets and that the two profit-maximizing firms are involved in a two-stage game. In the first stage, firms choose their coverages simultaneously and in the second stage, they compete $\grave{a}$ la Cournot in markets $\theta \in\left[0, \theta_{d}\right]$, while the incumbent acts as a monopolist in markets $\theta \in\left(\theta_{d}, \theta_{m}\right]$. The second stage leads to the usual monopoly and duopoly outcomes. If we let $Q(\theta)$ represent the industry's output at location $\theta$, then we have:

$$
Q(\theta)= \begin{cases}D\left(p_{d}\right) & \text { if } 0 \leq \theta \leq \theta_{d} \\ D\left(p_{m}\right) & \text { if } \theta_{d}<\theta \leq \theta_{m}\end{cases}
$$

where $p_{m}$ is the monopolistic price and $p_{d}$ is the duopolistic price. Since we assumed a zero marginal cost, $p_{m}$ is such that $\varepsilon\left(p_{m}\right)=1$ and $p_{d}$ is such that $\varepsilon\left(p_{d}\right)=\frac{1}{2}$. Not surprisingly, $p_{m}>p_{d}$, so that $r\left(p_{m}\right)>r\left(p_{d}\right)$. In duopolistic markets, each firm supplies $\frac{D\left(p_{d}\right)}{2}$.

In the first stage, the incumbent and the entrant maximize their aggregate profits choosing their coverages $\theta_{m}$ and $\theta_{d}$, respectively, in $[0,1]$. These profits are $\Pi_{I}\left(\theta_{d}, \theta_{m}\right)=\frac{1}{2} F\left(\theta_{d}\right) r\left(p_{d}\right)+\left(F\left(\theta_{m}\right)-\right.$ $\left.F\left(\theta_{d}\right)\right) r\left(p_{m}\right)-k H\left(\theta_{m}\right)$ for the incumbent and $\Pi_{E}\left(\theta_{d}, \theta_{m}\right)=\frac{1}{2} F\left(\theta_{d}\right) r\left(p_{d}\right)-k H\left(\theta_{d}\right)$ for the entrant. Letting $\tilde{\theta}_{i}$ be the optimal coverage for firm $i$, we obtain:

$$
\begin{aligned}
& \tilde{\theta}_{m}=\min \left\{\frac{r\left(p_{m}\right)}{k}, 1\right\}, \\
& \tilde{\theta}_{d}=\min \left\{\frac{r\left(p_{d}\right)}{2 k}, 1\right\} .
\end{aligned}
$$

Consider the likely case where $\tilde{\theta}_{m}<1$. Then it is straightforward to see that the incumbent's coverage is lower and the entrant's coverage is greater than the first-best incumbent's coverage and the first-best entrant's coverage, respectively. In addition, given that prices are strictly positive, that the industry is served by more than one firm, and that consumers' surpluses vary across markets, it follows that our UM benchmark fails to meet any of the four requirements for a firstbest outcome, and thus that the regulator's intervention is required a priori. Our interest is to analyze more specifically the extent to which the equity requirement can or cannot be met when this intervention takes the form of a USO. 


\section{USOs without Pricing Constraints}

We now study the imposition of USOs and we compare different combinations of constraints in terms of social welfare. We separate cases with or without the UP constraint because their analyses are different. In this section, we start with the simplest cases where no UP constraint is imposed.

Without UP, the industry profit constraint is:

$$
\Pi\left(\theta_{d}, \theta_{m}\right) \equiv F\left(\theta_{d}\right) r\left(p_{d}\right)+\left(F\left(\theta_{m}\right)-F\left(\theta_{d}\right)\right) r\left(p_{m}\right)-k\left(H\left(\theta_{d}\right)+H\left(\theta_{m}\right)\right) \geq 0 .
$$

Note that this function is additively separable in $\theta_{m}$ and $\theta_{d}$. It is then clear that increasing duopolistic coverage or making the incumbent extend coverage above its preferred coverage decreases industry profit, i.e.

$$
\begin{aligned}
& \frac{\partial \Pi\left(\theta_{d}, \theta_{m}\right)}{\partial \theta_{d}}=f\left(\theta_{d}\right)\left[r\left(p_{d}\right)-r\left(p_{m}\right)-k \theta_{d}\right]<0, \\
& \frac{\partial \Pi\left(\theta_{d}, \theta_{m}\right)}{\partial \theta_{m}}=f\left(\theta_{m}\right)\left[r\left(p_{m}\right)-k \theta_{m}\right] \leq 0 \text { if } \theta_{m} \geq \tilde{\theta}_{m} .
\end{aligned}
$$

\subsection{CC}

The CC is the basic component of USOs and it can be used as the sole USO component in practice. This type of USO scheme is modeled as a three-stage game. In the first stage, the regulator sets $\theta_{m}$ in order to maximize social welfare, subject to the industry profit constraint. In the second stage, the entrant chooses $\theta_{d}$ in order to maximize profit. In the third stage, firms choose their output simultaneously at each location.

The last stage is the same as in the UM benchmark, so the equilibrium industry output is given by (3). Since the entrant chooses its coverage independently of $\theta_{m}$, the second stage still leads to $\theta_{d}=\tilde{\theta}_{d}$. Then the regulator's problem in the first stage is:

$$
\begin{array}{ll}
\max _{\theta_{m}} & F\left(\tilde{\theta}_{d}\right) \phi\left(v\left(p_{d}\right)\right)+\left(F\left(\theta_{m}\right)-F\left(\tilde{\theta}_{d}\right)\right) \phi\left(v\left(p_{m}\right)\right)+\left(\left(1-F\left(\theta_{m}\right)\right) \phi(\epsilon)\right. \\
\text { s.t. } & \Pi\left(\tilde{\theta}_{d}, \theta_{m}\right) \geq 0 \\
& \theta_{m} \leq 1 .
\end{array}
$$

Let $\theta_{m}^{c}$ denote the optimal solution: as the objective function is strictly increasing, ${ }^{18}$ we have $\theta_{m}^{c}=\min \left\{\left\{\theta_{m} \mid \Pi\left(\tilde{\theta}_{d}, \theta_{m}\right)=0\right\}, 1\right\}$. Then one can state:

Proposition 1 Market coverage under CC cannot be lower than that under UM but never exceeds the first-best market coverage, i.e. $\tilde{\theta}_{m} \leq \theta_{m}^{c} \leq \theta_{m}^{*}$.

\footnotetext{
${ }^{18}$ The derivative of the objective function is $f\left(\theta_{m}\right)\left[\phi\left(v\left(p_{m}\right)\right)-\phi(\epsilon)\right]>0$.
} 
As a result, the $\mathrm{CC}$ improves both equity and participation efficiency, but as $\theta_{m}^{c}$ is independent of the regulator's aversion to inequality, imposition of $\mathrm{CC}$ cannot be specifically attributed to an equity concern.

\subsection{CC and LC}

The LC is an instrument that allows the regulator to calibrate the competition on covered markets. The benefit of increasing the entrant's coverage is the improvement in the allocative efficiency because the gap between the price and the marginal cost is reduced. The cost is the deterioration of the productive efficiency because the capital cost is duplicated in what would otherwise be a natural monopoly industry; because of the profit constraint, this introduces a trade-off between $\theta_{d}$ and $\theta_{m}$. There is also a cost in terms of equity because the price reduction on markets that become duopolistic increases the surplus gap between served and unserved consumers.

USOs under $\mathrm{CC}+\mathrm{LC}$ is a two-stage game. In the first stage, the regulator sets $\theta_{m}$ and $\theta_{d}$ in order to maximize social welfare, subject to the industry's non-negative profit constraint. In the second stage, firms choose their output simultaneously at each location.

The second stage is the same as in the UM benchmark, so the equilibrium outputs are given by (3). Then, the regulator's problem in the first stage is:

$$
\begin{array}{rl}
\max _{\theta_{m}, \theta_{d}} & F\left(\theta_{d}\right) \phi\left(v\left(p_{d}\right)\right)+\left(F\left(\theta_{m}\right)-F\left(\theta_{d}\right)\right) \phi\left(v\left(p_{m}\right)\right)+\left(1-F\left(\theta_{m}\right)\right) \phi(\epsilon) \\
\text { s.t. } & \Pi\left(\theta_{d}, \theta_{m}\right) \geq 0 \text { and } 1 \geq \theta_{m} \geq \theta_{d} \geq 0 .
\end{array}
$$

The coverages obtained under the $\mathrm{CC}$ are clearly feasible under $\mathrm{CC}+\mathrm{LC}$, so joining the $\mathrm{LC}$ to the CC cannot decrease social welfare. However, a more precise analysis of the solution is needed to evaluate the role of USOs in terms of equity.

First, for the cases where $\rho>1$ or $\rho \rightarrow 1$, then $\phi(\epsilon) \rightarrow-\infty$, so that the regulator requires ubiquity $\left(\theta_{m}=1\right)$ for the incumbent or, if not feasible, chooses the largest coverage possible. When ubiquity is feasible ${ }^{19}$, the regulator could in principle consider the trade-off between equity and efficiency among covered markets according to its exact value of $\rho$. As $\phi\left(v\left(p_{d}\right)\right)-\phi\left(v\left(p_{m}\right)\right)>0$, however, $W_{\rho}$ is maximized when $\theta_{d}$ takes its highest value feasible, whatever is $1<\rho<\infty .{ }^{20}$ In other words, only allocative efficiency is in fact considered for covered markets. We are then in a situation where, because of the profit constraint, the leximin solution prevails not only for $\rho \rightarrow \infty$, but for all $\rho>1$ and $\rho \rightarrow 1$. For this reason, hereafter, we collapse these cases to $\rho \rightarrow 1$.

\footnotetext{
${ }^{19}$ If ubiquity is not feasible, then $\theta_{d}=0$ in order to get the largest incumbent's coverage possible.

${ }^{20}$ If $\rho \rightarrow \infty$, then the regulator becomes Rawlsian for the covered markets and is indifferent to any $\theta_{d}<\theta_{m}$ as $v\left(p_{m}\right)$ remains the lowest utility.
} 
Second, if $\rho<1$, the trade-off between duopolistic and monopolistic coverages can be interpreted in terms of a comparison of the marginal rate of substitution between coverages and their relative marginal opportunity costs. More precisely, let $\Delta(\rho) \equiv \frac{\phi\left(v\left(p_{d}\right)\right)-\phi\left(v\left(p_{m}\right)\right)}{\phi\left(v\left(p_{m}\right)\right)-\phi(\varepsilon)}$ be the marginal rate of substitution of monopolistic coverage for duopolistic coverage and $\Gamma\left(\theta_{d}, \theta_{m}\right) \equiv \frac{k \theta_{d}+r\left(p_{m}\right)-r\left(p_{d}\right)}{k \theta_{m}-r\left(p_{m}\right)}$ be the ratio of the marginal opportunity cost of duopolistic coverage to monopolistic coverage. ${ }^{21} \Delta(\rho)$ then measures the regulator's preference for competition, while $\Gamma\left(\theta_{d}, \theta_{m}\right)$ measures the opportunity cost of competition. Preference for competition is unsurprisingly the highest when the regulator is utilitarist and it decreases with aversion to inequality: ${ }^{22}$ this comes directly from the fact that the relative weight given to unserved consumers increases with aversion to inequality.

Under a binding profit constraint, a necessary condition for optimal coverages is then the equalization of the marginal rate of substitution to the ratio of marginal costs unless one of the constraints $1 \geq \theta_{m} \geq \theta_{d} \geq 0$ is binding, i.e. unless $\theta_{d}=0, \theta_{m}=1$, or $\theta_{d}=\theta_{m} \cdot{ }^{23}$ Corner solutions $\theta_{d}=0$ or $\theta_{m}=1$ occur when duopolistic markets have low value to the regulator in the sense that the marginal rate of substitution is lower than the marginal opportunity cost for any feasible solution. In such a case, the regulator wants to expand monopolistic markets as much as it can: if the profit constraint makes ubiquity impossible, the regulator chooses $\theta_{d}=0$ in order to have the highest market coverage possible; if ubiquity is possible, it is implemented and duopolistic markets are then expanded as far as possible. Hereafter, we exclude the possibility of corner solutions for a utilitarist regulator: this would correspond to a case where increasing competition is always less efficient than extending market coverage, so that there would be no trade-off between efficiency and equity and the optimal solution would be independent of the regulator's aversion to inequality. ${ }^{24}$ In contrast, $\theta_{d}=\theta_{m}$ occurs when competition is highly efficient, so that a utilitarist regulator could wish to extend duopolistic markets as far as possible. But as the value of the marginal duopolistic market decreases with aversion to inequality, such a solution is possible only for sufficiently low aversion to inequality. The following lemma presents the conditions under which an interior solution for both $\theta_{d}$ and $\theta_{m}$ (i.e. $\left.0<\theta_{d}<\theta_{m}<1\right)$ prevails.

\footnotetext{
${ }^{21}$ Note that $\Gamma\left(\theta_{d}, \theta_{m}\right)$ decreases with $k$ as increasing network costs makes coverage of distant markets more expansive, and thus, reduces the relative cost of duopolistic markets.

${ }^{22}$ This is formally shown in the proof of Lemma 1.

${ }^{23}$ Full derivation of the first-order conditions is given in the proof of Lemma 1.

${ }^{24}$ Note that this would notably occur with low capacity cost $k$, while the context of network industries suggests that these capacity costs are significant.
} 
Lemma 1 Assume that the profit constraint is binding and let:

$$
\begin{aligned}
\tau_{d} & \in(0,1) \text { be such that } F\left(\tau_{d}\right)\left(r\left(p_{m}\right)-r\left(p_{d}\right)\right)+k H\left(\tau_{d}\right)=r\left(p_{m}\right)-k H(1), \\
\tau_{m} & \in\left(\frac{r\left(p_{m}\right)}{k}, 1\right) \text { be such that } F\left(\tau_{m}\right) r\left(p_{m}\right)=k H\left(\tau_{m}\right) .
\end{aligned}
$$

If

$$
\Delta(0) \geq \max \left\{\Gamma\left(\tau_{d}, 1\right), \Gamma\left(0, \tau_{m}\right)\right\},
$$

then there exists an interval $[\underline{\rho}, \bar{\rho}]$, where $0 \leq \underline{\rho}<\bar{\rho}<1$, such that

$$
0<\theta_{d}<\theta_{m}<1, \forall \rho \in[\underline{\rho}, \bar{\rho}] .
$$

Moreover, $\underline{\rho}=0$ if $\Delta(0)<1$.

As $\tau_{d}$ is the duopolistic coverage when $\theta_{m}=1$ and $\tau_{m}$ is the maximal market coverage with $\theta_{d}=0$, assumption (10) is the condition that excludes corner solutions $\theta_{d}=0$ or $\theta_{m}=1$ for an utilitarist regulator. Then, the proposition allows to characterize the optimal solution according to different values of $\rho$. Considering continuous increases from $\rho=0$ to $\rho=1$, we obtain the following results: (i) in the event that the marginal rate of substitution is sufficiently high, covered markets are all duopolistic when aversion to inequality is low $(\rho \in[0, \underline{\rho}]),{ }^{25}$ (ii) there necessarily exists a range of $\rho$ for which the solution is interior for both $\theta_{d}$ and $\theta_{m}$ (i.e. $0<\theta_{d}<\theta_{m}<1$ ), (iii) there is a threshold value of $\rho$ over which covering all markets becomes the prevalent objective, so that monopolistic markets are pushed as far as possible and duopolistic markets remain only if ubiquity is possible - we then have either $\theta_{d}=0$ and $\theta_{m}=\tau_{m}$ or $\theta_{d}=\tau_{d}$ and $\theta_{m}=1$.

The FOCs also show that the marginal profit of monopolistic markets, $r\left(p_{m}\right)-k \theta_{m}$, is negative for all cases, ${ }^{26}$ thereby showing that the market coverage is greater than that in an UM. Furthermore, in the range of interior solutions, the addition of the LC to the CC makes the optimal solution directly dependent on the regulator's aversion to inequality, as shown in the following proposition.

Proposition 2 Under $C C+L C$ and condition (10),

(i) $\frac{d \theta_{m}}{d \rho} \geq 0, \forall \rho \in[0,1)$

(ii) $\frac{d \theta_{m}}{d \rho}>0$ for $\forall \rho \in[0, \bar{\rho})$ and $\frac{d \theta_{d}}{d \rho}<0, \forall \rho \in(\underline{\rho}, \bar{\rho})$.

\footnotetext{
${ }^{25}$ This case does not happen if $\Delta(0)<1$. From Anderson and Renault [2], a sufficient condition for $\Delta(0)<1$ is that $\Omega(p) \leq \frac{r\left(p_{m}\right)}{r\left(p_{d}\right)}-2$, i.e. that the demand is not "too concave".

${ }^{26}$ Intuitively, an optimum cannot be attained at $r\left(p_{m}\right)-k \theta_{m} \geq 0$ as increased monopolistic coverage brings an additional revenue instead of a cost, in contradiction with the fact that the profit constraint is binding.
} 
The fact that $\frac{d \theta_{m}}{d \rho}$ and $\frac{d \theta_{d}}{d \rho}$ have opposite signs for $\rho \in(\underline{\rho}, \bar{\rho})$ comes from the profit constraint: as an increase in $\theta_{m}$ reduces profit, it must be compensated by reduced competition in order to increase the revenue in markets that were already covered. Then, because the utility gap between uncovered and covered markets is greater than that between monopolistic and duopolistic markets, a greater aversion to inequality makes an increase in monopolistic markets more valuable, which compels the regulator to extend the monopolistic coverage. Furthermore, decreasing duopolistic coverage decreases inequality between served and unserved consumers as the average price on covered markets is increased.

In brief, imposing USOs can be used specifically for equity purposes provided that a LC is imposed. This promotes equity in two ways: (i) by improving the participation efficiency; and (ii) by reducing the allocative efficiency, so the utility gap between served and unserved consumers is reduced.

\section{UP Constraint}

Under a uniform price constraint, the incumbent is constrained to choose, at each location, a quantity such that the resulting price is identical at all of the covered locations. This creates interdependence among markets, so that the last stage does not lead to the usual monopoly and duopoly outcomes. We first present the impact of UP without coverage constraints in order to understand the basic properties of uniform pricing. This has been extensively analyzed in Poudou and Roland [23] and we report their main results here. We then consider the addition of CC and LC in turn with the aim of determining to what extent the choice of imposing UP depends on the regulator's aversion to inequality.

\subsection{UP Imposed Separately}

When UP is imposed separately, the game has the same structure as in the UM game, except for the fact that the incumbent is constrained in its choice of output in the second stage.

Consider the second stage and let $q_{I}$ and $q_{E}$ be the incumbent's and entrant's outputs, respectively, in duopolistic markets. ${ }^{27}$ The entrant is not constrained and its problem corresponds to a classic Cournot problem:

$$
\max _{q_{E}} F\left(\theta_{d}\right) P\left(q_{I}+q_{E}\right) q_{E}-k H\left(\theta_{d}\right)
$$

\footnotetext{
${ }^{27}$ As demands are the same in all markets, equilibrium quantities will be identical in all duopolistic markets. The same argument will apply to monopolistic markets. See Poudou and Roland [23] for details.
} 
The incumbent must ensure that the price is the same on all markets. Letting $Q$ represent its output in monopolistic markets, this implies that $Q=q_{I}+q_{E}$. Then $q_{I}$ can be interpreted as the "basic" output the incumbent supplies on all markets and $q_{E}$ represents the output it must pick up in monopolistic markets because of the absence of the entrant. In other words, the incumbent must "offset" the absence of the entrant in monopolistic markets by supplying $q_{E}$ on top of $q_{I}$. The incumbent's problem can then be written as:

$$
\max _{q_{I}} F\left(\theta_{m}\right) P\left(q_{I}+q_{E}\right)\left(q_{I}+(1-s) q_{E}\right)
$$

where $P(\cdot)$ is the inverse demand function and $s \equiv \frac{F\left(\theta_{d}\right)}{F\left(\theta_{m}\right)}$ represents the share of duopolistic markets in covered markets. As derived in Poudou and Roland [23], the equilibrium quantities and price are functions of $s$ and are implicitly given by:

$$
\begin{aligned}
\varepsilon(\bar{p}(s)) & =\frac{1}{1+s}, \\
q_{E} & =D(\bar{p}(s)) \varepsilon(\bar{p}(s)), \\
q_{I} & =s q_{E},
\end{aligned}
$$

where the uniform price is denoted $\bar{p}(s)$. Output in each market is then $Q=(1+s) q_{E}$ and the term $\frac{1}{1+s}$ can then be viewed as the incumbent's output share of covered markets ${ }^{28}$, which is a convex function of $s$. Note that when $s=0$, all markets are monopolistic, so the uniform price is the usual monopolistic price $p_{m}$. When $s=1$, all markets are duopolistic, so the price is $p_{d}$. Increases in $s$ from an initial point in $[0,1)$ put covered markets in an increasingly duopolistic configuration. Under our assumptions on the elasticity of the slope of the demand function, Poudou and Roland [23] showed that $\bar{p}(s)$ is strictly decreasing and strictly convex. Then further increases in $s$ lead to smaller decreases in the incumbent's output share and, by convexity of $\bar{p}(s)$, to smaller decreases in equilibrium price towards the duopolistic level.

The following lemma provides the key properties of the second-stage equilibrium.

Lemma 2 If $\Omega(p) \geq-1$ and $\Omega^{\prime}(p) \leq 0, \forall p$, then, for a given $\left(s, \theta_{m}\right)$,

(i) $\bar{p}(s) \leq(1-s) p_{m}+s p_{d}$, i.e. the average price per served consumer does not increase with $U P$;

(ii) the industry profit is at least as great with UP than that without UP.

Part (i) is the direct consequence of the convexity of $\bar{p}(s)$. Part (ii) comes from the concavity of the revenue function. To see this, let $\tilde{p}(s)$ be such that $r(\tilde{p}(s))=\operatorname{sr}\left(p_{d}\right)+(1-s) r\left(p_{m}\right)$, where $\tilde{p}(s)$

\footnotetext{
${ }^{28}$ The incumbent supplies $(1+s) q_{E}$ in monopolistic markets and $s q_{E}$ is duopolistic markets, while aggregate output is constant at $(1+s) q_{E}$ in each market. Its share of output in covered markets is then $\frac{(1+s) q_{E}-s q_{E}}{(1+s) q_{E}}=\frac{1}{1+s}$.
} 
can be interpreted as the "certainty equivalent" of the average price obtained per served market without UP. We must have that $\tilde{p}(s) \leq \bar{p}(s)$; otherwise, profit would be higher for the entrant at price $\tilde{p}(s)$ than at price $\bar{p}(s)$, which contradicts the fact that $\bar{p}(s)$ is an equilibrium price. Since both prices are less than $p_{m}, r(\bar{p}(s)) \geq r(\tilde{p}(s))$ and the result follows because costs are fixed by the assumption of given coverages.

The basic argument that UP is prima facie an equity-oriented policy is reflected in the next lemma, which shows that, for given market coverages, social welfare is greater with UP than without it provided that the regulator has a sufficiently strong aversion to inequality. To apprehend this fact, note that, for fixed $\theta_{m}$, uncovered markets are not affected by UP, while prices, and thus consumer utilities, are equalized over covered markets. In virtue of the "independence of unconcerned agents" the comparison of social welfare between the two situations then depends only on covered markets. The fact that UP equalizes consumers' utilities over covered markets becomes the determining factor in comparing social welfare when $\rho$ is sufficiently high.

Lemma 3 For a given $\left(\theta_{d}, \theta_{m}\right)$, where $\theta_{d}>0$, there exists a level of $\rho$ over which social welfare is greater with UP than that without it.

The reason for which UP does not increase welfare for all $\rho$ is that the indirect utility function $v$ is convex. Thus, it is possible, for instance, that a utilitarian regulator prefers unequal prices because the aggregate consumers' utility is then lower under UP despite the fact that $\bar{p}(s) \leq s p_{d}+(1-s) p_{m}$. However, because increasing $\rho$ amounts to the "concavification" of individual utilities $v$, then there is necessarily a $\rho$ over which the preferences of the regulator dominate those of the consumers. ${ }^{29}$

In the first stage, the entrant chooses $\theta_{d}$, or equivalently $s$, given $\theta_{m}$ and solves:

$$
\max _{s} s F\left(\theta_{m}\right) \frac{r(\bar{p}(s))}{1+s}-k H\left(F^{-1}\left(s F\left(\theta_{m}\right)\right)\right),
$$

where $\frac{s}{1+s}$ is the proportion of total demand served by the entrant. Poudou and Roland [23] show that the objective function of (14) is concave in $s$ under a technical condition that is met for a large class of demand functions, including strictly concave, linear and exponential demand functions. Since $\bar{p}(s) \geq p_{d}$, markets are more profitable for the entrant when a uniform constraint is imposed. As a result, for a fixed $\theta_{m}$, the entrant expands its coverage.

Lemma 4 For a given $\theta_{m}$, the entrant's coverage under UP is greater than or equal to the entrant's coverage without UP. If the incumbent coverage is fixed at $\theta_{m}=\theta_{m}^{c}$, then entrant's coverage under $U P$ is strictly greater than entrant's coverage under CC.

\footnotetext{
${ }^{29}$ The average price is lower under UP, i.e., $\bar{p}(s) \leq s p_{d}+(1-s) p_{m}$, so it is still possible that UP is also preferred by a utilitarian regulator (and thus by all types of regulators). This is the case in our numerical example.
} 
Assuming that $s$ is given, the incumbent solves the following problem:

$$
\max _{\theta_{m}} \Pi_{I}=F\left(\theta_{m}\right) \frac{r(\bar{p}(s))}{1+s}-k H\left(\theta_{m}\right),
$$

where $\frac{1}{1+s}$ is the proportion of the total demand served by the incumbent. The first-order condition is then:

$$
\theta_{m}=\min \left\{\frac{r(\bar{p}(s))}{k(1+s)}, 1\right\}
$$

Comparing (16) to (4) shows that the incumbent's coverage is lower under UP than that in an UM for any $s>0 .{ }^{30}$ This comes from the fact that UP reduces the price that the incumbent receives, so the marginal benefit of coverage is reduced, and thus the market coverage is reduced. We obtain the following proposition as a result.

Proposition 3 There necessarily exists a level of $\rho$ over which social welfare under UP is less than social welfare in an UM.

This is because, for a regulator with sufficiently high aversion to inequality, the reduction of consumers' participation caused by UP cannot be compensated in terms of social welfare by any gain of allocative efficiency in covered markets. It also follows directly that UP cannot be a substitute for the CC if a regulator has a sufficiently strong aversion to inequality: the difference in market coverage between UP and the CC is even greater than that between UP and an UM. As social welfare obtained under $\mathrm{CC}+\mathrm{LC}$ is never below the one obtained under the $\mathrm{CC}$, this also means that $\mathrm{CC}+\mathrm{LC}$ is preferred to $\mathrm{UP}$ for this same regulator.

Proposition 4 There necessarily exists a level of $\rho$ over which using UP instead of $C C$ or $C C+L C$ decreases social welfare.

In brief, contrary to intuition, the UP constraint tends to increase inequality when used as the sole instrument because it makes the incumbent reduce market coverage. It is possible that a regulator with a low aversion to inequality prefers UP to a coverage control (i.e., $\mathrm{CC}+\mathrm{LC}$ ), but a regulator with a sufficiently high aversion to inequality will prefer to drop out UP and increase market coverage.

\footnotetext{
${ }^{30}$ This result is standard in the literature on universal service (see, for instance, Valletti et al. [24] for the case of price competition). Poudou and Roland [23] also showed that the decrease of $\theta_{m}$ leads to an increase of the share of duopolistic markets $s$. As $s$ and $\theta_{m}$ move in opposite directions, the impact on $\theta_{d}=F^{-1}\left(s F\left(\theta_{m}\right)\right)$ is however ambiguous.
} 


\subsection{Inclusion of the $\mathrm{CC}(\mathrm{CC}+\mathrm{UP})$}

We now consider the three-stage game that is equivalent to the one in Section 4.1, except that UP is imposed on the incumbent in the third stage. Thus, in the first stage, the regulator sets $\theta_{m}$ in order to maximize social welfare, subject to the industry profit constraint. In the second stage, the entrant chooses $\theta_{d}$ in order to maximize profit. In the third stage, firms choose their output simultaneously at each location, but the incumbent must ensure that the UP constraint is met.

The entrant's problem in the second stage is the same as that in UP.

In the first stage, the regulator chooses the incumbent's coverage in order to maximize welfare:

$$
\begin{array}{cl}
\max _{\theta_{m}} & F\left(\theta_{m}\right) \phi\left(v\left(\bar{p}\left(s\left(\theta_{m}\right)\right)\right)\right)+\left(1-F\left(\theta_{m}\right)\right) \phi(\epsilon) \\
\text { s.t. } & r\left(\bar{p}\left(s\left(\theta_{m}\right)\right)\right) F\left(\theta_{m}\right)-k\left[H\left(F^{-1}\left(s\left(\theta_{m}\right) F\left(\theta_{m}\right)\right)\right)+H\left(\theta_{m}\right)\right] \geq 0,
\end{array}
$$

where $s\left(\theta_{m}\right)$ is the reaction function of the entrant obtained in the second stage. Similarly to the case where only the CC is imposed, the CC+UP market coverage is driven only by the profit constraint and is thus independent of the regulator's aversion to inequality. Moreover, no statement can be made about whether the incumbent's coverage is greater than, less than, or equal to the CC coverage. To understand why, assume an initial situation where CC is imposed, so that $\theta_{m}=\theta_{m}^{c}$ and $\theta_{d}=\tilde{\theta}_{d}<\theta_{m}^{c}$. Then, by virtue of Lemma 4, the entrant wants to increase its coverage. If the regulator reacts by changing $\theta_{m}$, then there are two countervailing impacts on the incumbent's profit: $(i)$ a direct effect, which is negatively correlated to $\theta_{m}$ because the marginal profit of the incumbent for a given $s$ is already negative under CC; and (ii) an indirect impact from the reaction $s\left(\theta_{m}\right)$, which is positively correlated because $s^{\prime}\left(\theta_{m}\right)$ is negative ${ }^{31}$, while the incumbent's profit decreases with the entrant's share for a given $\theta_{m}$. The overall impact on industry profit, which represents the capacity of the regulator to extend market coverage, is thus ambiguous. Consequently, the addition of UP to CC cannot ensure an increase of welfare, as shown in the following proposition.

Proposition 5 If the incumbent's coverage under $C C+U P$ is less than the incumbent's coverage under $C C$, there exists a $\rho$ over which social welfare under $C C+U P$ is less than welfare under $C C$.

As a result, the claim that the most common form of USO, $\mathrm{CC}+\mathrm{UP}$, is an equity-driven policy is not supported by theoretical analysis in general. For instance, consider the case of a linear demand $D(p)=2-p,{ }^{32}$ a uniform distribution of consumers over $[0,1]$ and a cost parameter of

\footnotetext{
${ }^{31}$ See Poudou and Roland [23].

${ }^{32}$ Then $p_{m}=1$ and $p_{d}=\frac{2}{3}$.
} 
$k=2$. Because market is more profitable for the entrant with UP, its coverage increases from $22 \%$ of the market under the $\mathrm{CC}$ to $28 \%$ under CC+UP. However, because of the profit constraint, the increased coverage of the entrant forces the regulator to reduce the incumbent's coverage from $95 \%$ of the market under the $\mathrm{CC}$ to $90 \%$ under CC+UP. Thus Proposition 5 applies. For this case, the increase of aggregate consumers' surplus because of reduced and equalized price is greater than its decrease following lower market coverage, so that a utilitarist regulator would opt for CC+UP, as can be seen in Figure 1 for $\rho=0$. Thus, joining UP to CC improves allocative efficiency in this example. But the social welfare function weighs more heavily the decrease in market coverage the more averse to inequality is the regulator, so that $\mathrm{CC}$ becomes preferred to $\mathrm{CC}+\mathrm{UP}$ for regulators with $\rho \geq 0.59$.

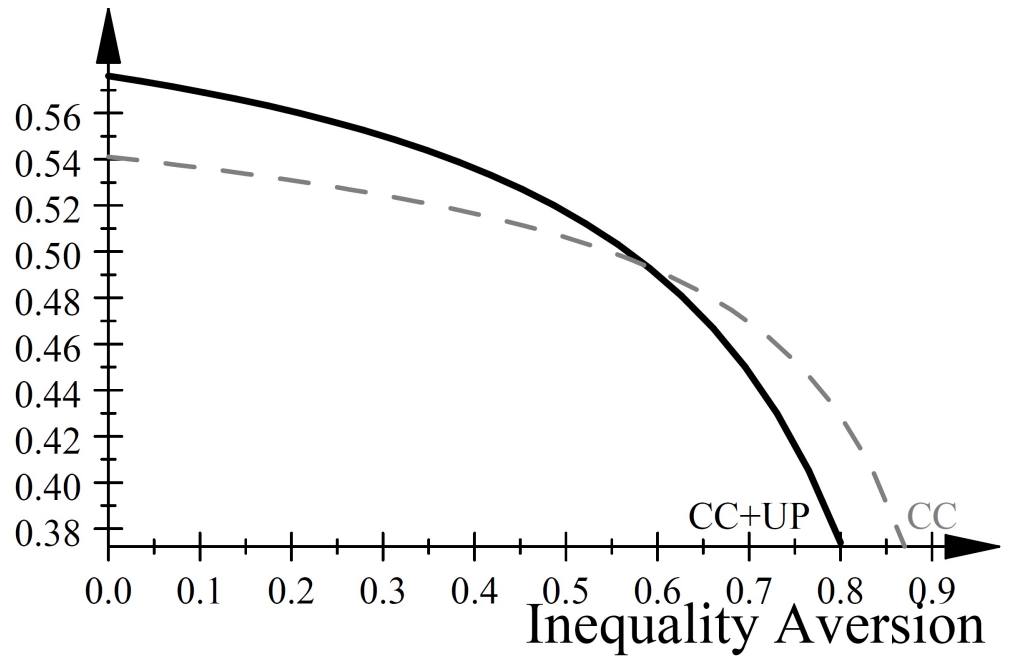

Figure 1: Social Welfare $W_{\rho}$

Furthermore, the Atkinson inequality index is greater under CC+UP than under CC for all $\rho \in(0,1)$, as shown in Figure 2. This suggests that, even for low levels of $\rho$, equity improvements following the imposition of an identical price to served consumers never offset the increased inequality because of the reduction of served markets. The fact that the allocation under CC+UP is more efficient but less equitable than the one under $\mathrm{CC}$ is the clearest at $\rho=0.59$, where social welfare is the same under both $\mathrm{CC}+\mathrm{UP}$ and $\mathrm{CC}$.

Note that nothing excludes the possibility that the incumbent's coverage be greater under $\mathrm{CC}+\mathrm{UP}$ than under $\mathrm{CC}$, so that the allocation becomes more equitable under $\mathrm{CC}+\mathrm{UP}$. The point is that the addition of uniform pricing to the basic CC of a USO cannot be considered as an equity-oriented policy in general. 


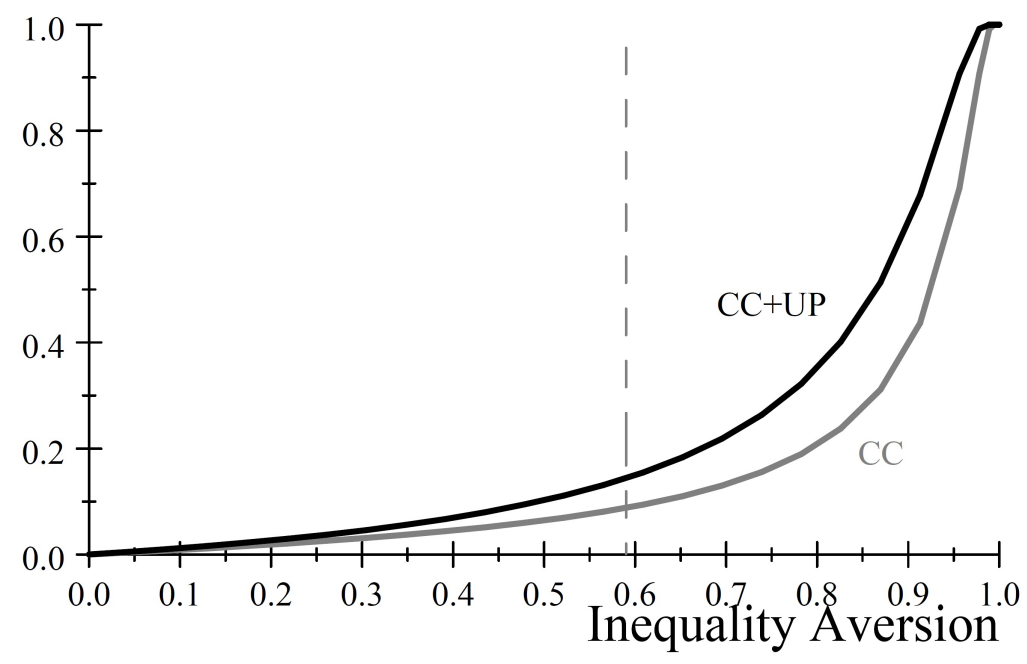

Figure 2: Atkinson Inequality Index

\subsection{Inclusion of the $\mathrm{LC}(\mathrm{CC}+\mathrm{LC}+\mathrm{UP})$}

The reason for which the regulator cannot ensure that the higher profit attributable to UP for a given coverage results in higher social welfare is that it has no direct control on the price, provided that $s$ is determined by the entrant. To make its policy reflect its equity objectives, the regulator can then bypass this difficulty by appending the LC constraint. Thus, under UP, the regulator's problem in stage 1 is:

$$
\begin{array}{ll}
\max _{\theta_{m}, s} & F\left(\theta_{m}\right) \phi(v(\bar{p}(s)))+\left(1-F\left(\theta_{m}\right)\right) \phi(\epsilon) \\
\text { s.t. } & r(\bar{p}(s)) F\left(\theta_{m}\right)-k\left[H\left(\theta_{d}\right)+H\left(\theta_{m}\right)\right] \geq 0 \\
& s=\frac{F\left(\theta_{d}\right)}{F\left(\theta_{m}\right)} .
\end{array}
$$

Lemma $2(i i)$ stated that, for a given pair $\left(s, \theta_{m}\right)$, the industry profit cannot decrease after the imposition of UP. This means that coverages $\left(\theta_{d}, \theta_{m}\right)$ that are feasible under CC+LC are feasible under $\mathrm{CC}+\mathrm{LC}+\mathrm{UP}$. Lemma 3 showed that, for a given pair $\left(s, \theta_{m}\right)$, there existed a value of $\rho$ for which social welfare is greater under UP than without it. This means that, starting with the $\mathrm{CC}+\mathrm{LC}$ coverages, we can increase welfare by introducing the UP constraint provided that $\rho$ is sufficiently high.

Proposition 6 (i) Social welfare under $C C+L C+U P$ is greater than or equal to social welfare under $C C+U P$. (ii) There exists a value of $\rho$ over which social welfare is greater under $C C+L C+U P$ than that under $C C+L C$. 


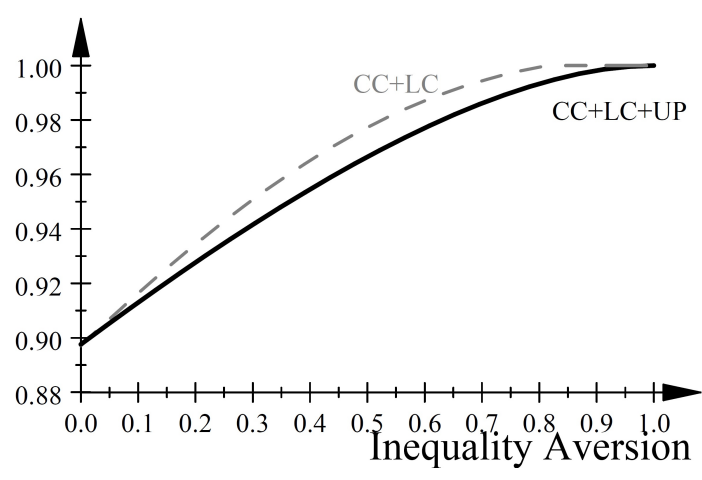

Figure 3: Incumbent's Coverage $\left(\theta_{m}\right)$

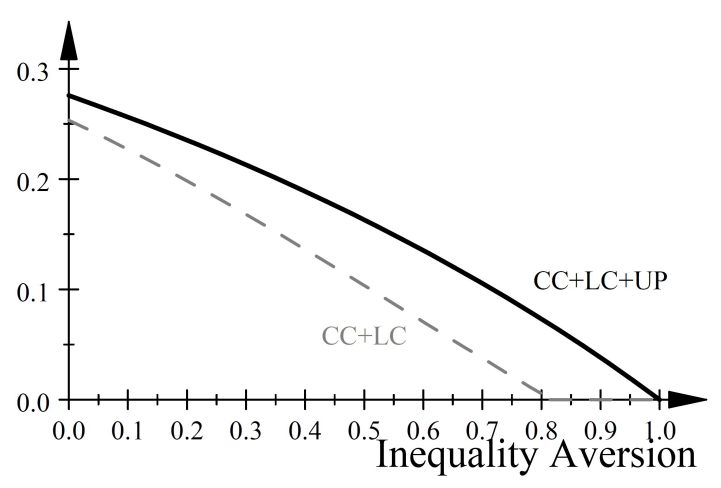

Figure 4: Entrant's Coverage $\left(\theta_{d}\right)$

The way that LC can increase welfare in part $(i)$ is by allowing to countervail the greater entrant's coverage under uniform pricing that was identified in Lemma 4 whenever this greater coverage leads to reduced welfare because of reduced incumbent's coverage, as shown in Proposition 5. In part ( $i i)$, adding $\mathrm{UP}$ to $\mathrm{CC}+\mathrm{LC}$ can increase welfare mainly by increasing the industry profitability, so that the feasible set of coverages is enlarged.

It is important to note that the fact that joining $\mathrm{UP}$ to $\mathrm{CC}+\mathrm{LC}$ increases welfare does not imply that it improves equity. This is because, by decreasing average price of served consumers, UP improves allocative efficiency by reducing the gap between price and marginal cost for given entrant's coverage (Lemma $2(i)$ ). Furthermore, an increase in the relative entrant's coverage brings a further reduction of this gap $\left(p^{\prime}(s) \leq 0\right)$. For a given $\rho$, it is then possible that the allocative efficiency gain is strong enough to make the regulator use the increased industry profit that UP brings to increase the entrant's share of the market at the expense of the incumbent's coverage. Then, the improvement of welfare can be made through an increase in allocative efficiency that more than compensates for less equity. To illustrate this, we use again the example of linear demand and uniform distribution of consumers considered in section 5.2. Here adding UP to CC+LC improves social welfare for all values of $\rho$. Figures 3 and 4 present the optimal coverages for $\mathrm{CC}+\mathrm{LC}$ and $\mathrm{CC}+\mathrm{LC}+\mathrm{UP}$ for this case. Using $\mathrm{CC}+\mathrm{LC}$ as the benchmark, we see that the regulator uses the higher industry profitability under the UP constraint to increase the entrant's coverage up to a point where the incumbent's coverage is reduced. In other words, the UP seems to be used more for increased allocative efficiency than for equity purposes.

To confirm this fact, Figure 5 isolates the part of social welfare that is explained by the equity consideration from the one that is explained by efficiency with the help of the Atkinson inequality index. We see that adding UP increases inequality for a sufficiently high aversion to inequality. For low $\rho$, i.e. for cases where the impact of unserved markets is relatively low in the evaluation 
of welfare, inequality is reduced under $\mathrm{CC}+\mathrm{LC}+\mathrm{UP}$ because inequality is reduced among served consumers. However, because the impact of unserved markets is increased with $\rho$, the fact that $\theta_{m}$ is lower under $\mathrm{CC}+\mathrm{LC}+\mathrm{UP}$ than that under $\mathrm{CC}+\mathrm{LC}$ increases inequality. This shows that the welfare gain of $\mathrm{CC}+\mathrm{LC}+\mathrm{UP}$ is due to an increased efficiency that is sufficiently strong to justify a less equitable outcome.

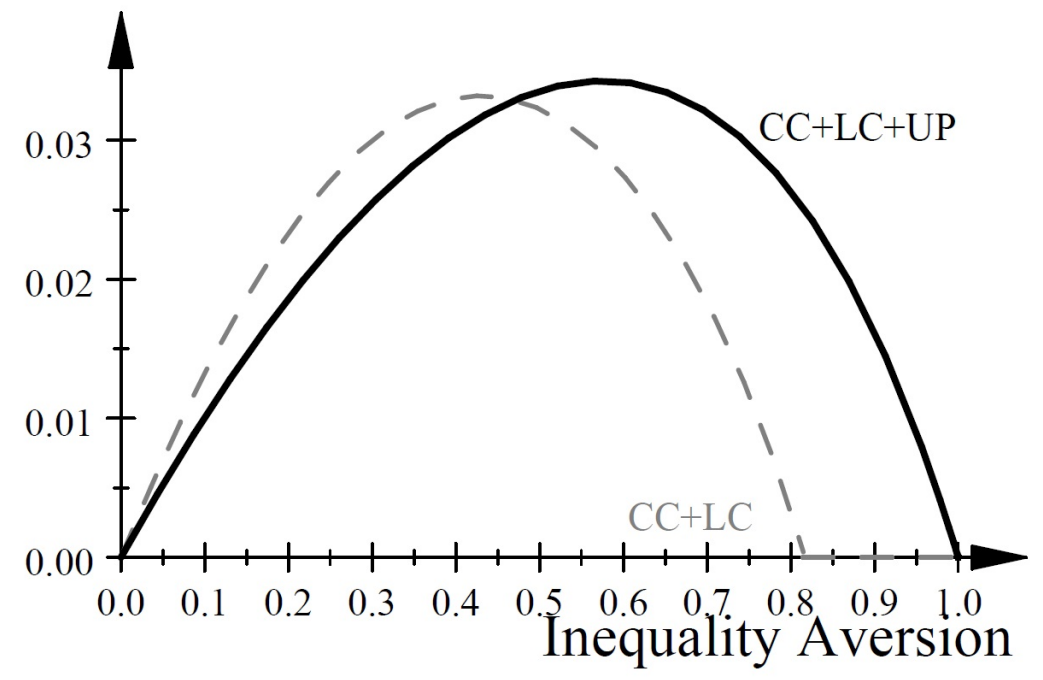

Figure 5: Atkinson Inequality Index

\section{Extension: Constraints on Transfers and Profits}

In practice, the assumption of the possibility of transferring profit between firms corresponds to the existence of a USO fund established to compensate the universal service provider. As we have considered in this paper, the fund can effectively be financed through lump-sum payments. This is the case, for instance, when licenses are allocated through auctions as in the telecom industry. But such lump-sum payments are generally not allowed to amount to the full profit of the firms. An important instance of this, mentioned by Gautier and Wauthy [17], is the requirement of "competitive neutrality" which guarantees the USO provider a profit equal to the UM outcome. In this section, we show that, although optimal coverages and social welfare are impacted by those limits on rent extraction, the basic relationships between optimal coverages and the regulator's aversion to inequality are maintained, provided that restrictions on transfers are not too severe. This means that restrictions on transfers does not change the working of USOs but impede their redistributive role. 
To model constraints on transfers, we first need to differentiate the origin of profit, i.e. whether profit is generated by the entrant or the incumbent. We thus denote by $\Pi_{I}$ and $\Pi_{E}$ the profit obtained under a specific scheme by the incumbent and the entrant, respectively. We represent constraints on lump-sum transfers by letting $\delta \in[0,1]$ be the "ease" of making such transfers ${ }^{33}$ and we let $\Pi_{i}^{0}$ be the minimal profit that firm $i$ is entitled to by regulation. As a result, instead of using the constraint of the problem (9) or the problem (17), we now use the following pair of constraints:

$$
\begin{aligned}
\Pi_{I}+\delta\left(\Pi_{E}-\Pi_{E}^{0}\right) & \geq \Pi_{I}^{0} \\
\Pi_{E}+\delta\left(\Pi_{I}-\Pi_{I}^{0}\right) & \geq \Pi_{E}^{0} .
\end{aligned}
$$

By setting $\delta=1$ and $\Pi_{I}^{0}=\Pi_{E}^{0}=0$, we reproduce the case considered up to now where transfers are not costly and are limited only by an industry-wide self-financing constraint. ${ }^{34}$ When $\delta=0$, no transfers are allowed and the regulator must ensure that firms attain their minimum profit target. Intermediate values of $\delta$ measures the capacity of extracting rent. Note that whenever a transfer is made with $\delta \in(0,1)$, only one of the constraints can be binding, which is because there can be a positive net transfer only in "one direction", i.e. either from the entrant to the incumbent or in the reverse direction. ${ }^{35}$ Constraint (19) is binding when a transfer is made from the entrant to the incumbent, while constraint (20) is binding for a transfer from the incumbent to the entrant. In order to make $\mathrm{CC}$ and $\mathrm{CC}+\mathrm{LC}$ feasible whatever is $\delta$, we assume that $\Pi_{i}^{0} \leq \tilde{\Pi}_{i}$ where $\tilde{\Pi}_{i}$ is the profit of firm $i$ under an $\mathrm{UM} .{ }^{36}$

It is clear that "hardening" the constraints through a decrease of $\delta$ or an increase of either $\Pi_{I}^{0}$ or $\Pi_{E}^{0}$ impedes the capacity of the regulator to increase welfare compared to the unregulated benchmark. However, the facts that profit does not appear in the objective function and that relative welfare of different market structures remain the same imply that the basic trade-off between $\theta_{d}$ and $\theta_{m}$ is not modified, so that the reduction of the transfer capacity of the regulator has an impact exclusively through the definition of the feasible set. Optimal solutions under different USO schemes are thus modified quantitatively, but their properties are qualitatively similar provided that their feasibility is maintained. To show this, we define $\delta^{0}$ as the minimal coefficient of ease of

\footnotetext{
${ }^{33} \delta$ can for instance be interpreted as a maximal allowed profit tax or $(1-\delta)$ can be interpreted as a unit transaction cost on lump-sum transfers.

${ }^{34}$ The industry profit constraint of problem (9) or (17) is then duplicated.

${ }^{35}$ If $(19)$ is binding and $\Pi_{I}-\Pi_{I}^{0} \neq 0$, we have $\Pi_{I}-\Pi_{I}^{0}=-\delta\left(\Pi_{E}-\Pi_{E}^{0}\right)$ and $\left(\Pi_{E}-\Pi_{E}^{0}\right)\left(1-\delta^{2}\right)>0$, which implies a transfer from the entrant to the incumbent. Similarly, if $(20)$ is binding and $\Pi_{E}-\Pi_{E}^{0} \neq 0$, we have a transfer from the incumbent to the entrant. If both constraints are binding, then $\Pi_{I}-\Pi_{I}^{0}=\Pi_{E}-\Pi_{E}^{0}=0$, implying that no transfer is made.

${ }^{36}$ Then UM coverages $\left(\tilde{\theta}_{d}, \tilde{\theta}_{m}\right)$ are always a feasible solution under these schemes. Note, however, that feasibility of uniform pricing becomes an issue even for the case of $\mathrm{CC}+\mathrm{LC}+\mathrm{UP}$.
} 
transfer that makes both the entrant's and the incumbent's coverages under CC+LC feasible under $\mathrm{CC}+\mathrm{LC}+\mathrm{UP}$.

Proposition 7 If $\Pi_{I}^{0} \leq \tilde{\Pi}_{I}$ and $\Pi_{E}^{0} \leq \tilde{\Pi}_{E}$, Propositions $2(i), 3,4,5$ and $6(i)$ hold and there exists a $\delta^{0} \in[0,1]$ such that Proposition 6 (ii) holds if $\delta \geq \delta^{0}$.

Condition $\delta \geq \delta^{0}$ is sufficient to ensure that $\mathrm{CC}+\mathrm{LC}+\mathrm{UP}$ improves welfare compared to $\mathrm{CC}+\mathrm{LC}$ if $\rho$ is sufficiently high, as in Proposition 6 (ii). But this condition is not necessary. For instance, when $\Pi_{E}^{0}=0, \mathrm{CC}+\mathrm{LC}+\mathrm{UP}$ is always feasible even if $\delta=0$. This is because competition can be reduced until the incumbent's profit is restored to the level obtained under CC+LC. ${ }^{37}$ It is then possible that $\mathrm{CC}+\mathrm{LC}+\mathrm{UP}$ increases welfare. Whether it does or not then depends on the severity of the needed competition shedding and of the resulting price increase. To illustrate this point, consider the requirement of competitive neutrality which, following Gautier and Wauthy [17] and Chone et al. [9], can be interpreted as ensuring the unregulated market profit $\tilde{\Pi}_{I}$ to the incumbent, i.e. as of having $\Pi_{E}^{0}=0$ and $\Pi_{I}^{0}=\tilde{\Pi}_{I}$. Then competitive neutrality is always feasible under $\mathrm{CC}+\mathrm{LC}+\mathrm{UP}{ }^{38}$ But if $\delta \leq \delta^{0}$, the desirability of uniform pricing depends on the importance and the consequences of the competition reduction required to maintain the incumbent's profit.

In brief, decreasing the ease of transfers unsurprisingly lowers welfare but preserves the basic trade-off involved in the choice of duopolistic and market coverages. However, the welfare-enhancing potential of uniform pricing is strongly linked to the possibility of making transfers between firms and this should be taken into account when implementing policies such as competitive neutrality.

\section{Conclusion}

We showed that when the market price level cannot be regulated directly and when no efficient transfer mechanism to consumers is available, the prima facie claim that USOs respond to equity considerations is not supported unless the regulator controls the competitive entry as well as the market coverage. This should not be a surprise because controlling the market structure can be a substitute for price regulation, which is itself a substitute for direct transfers. However, this fact

\footnotetext{
${ }^{37}$ This is always possible because, at the limit, if competition is eliminated, the incumbent obtains the monopoly profit on served markets, so that the initial CC coverage is feasible.

${ }^{38} \mathrm{~A}$ similar result is obtained by Gautier and Wauthy [9] in a price competition model where transfers are made from the proceeds of a unit tax on the entrant's output rather than from a lump-sum tax. The unit tax then relaxes competition and thus allows an indirect control on competition that has similar effects to our direct control through LC. They then show that competitive neutrality is feasible with some level of competition $\left(\theta_{d}>0\right)$.
} 
has been neglected in the literature. We also showed that the addition of a UP constraint to a LC and a CC increases social welfare when the regulator is free to transfer profits between firms, but, more surprisingly, it does not necessarily improve equity.

In conformity to most papers on USOs in a competitive context, our results rely on a duopolistic market structure. But, as it turns out that the capacity for USO to improve social welfare originates from the capacity to extract the industry rent, a natural question is to analyze to what extent our results stand in view of the potential entry of multiple firms. New possibilities are likely to occur in a model with more than one entrant. For instance, for given coverages, equilibria such as those studied by Gautier and Wauthy [16], where the incumbent submitted to UP abandon competitive markets to be able to practice monopoly prices in high-cost markets, is not possible in our duopolistic framework but could appear with the expansion of competition. Although the determination of optimal coverages would become more complex, the important point of this paper that LC is needed remains: as the regulator controls entry, it can choose to restrict the industry to duopolistic competition even in presence of many potential entrants. So the presence of competition increases the feasible set of solutions and can only increase welfare. However, as the number of potential entrants increases, the opportunity cost of controlling entry against a unregulated market increases in terms of allocative efficiency, so that the comparative advantage of USO as a regulatory instrument against other policies, including laissez-faire, would probably be reduced.

In practice, the use of USOs by an inequality averse regulator should follow a cost-benefit analysis in a second-best world where a panoply of redistributive instruments can exist. An extension of our study should involve the relaxation of the assumption of the impossibility of transfers to consumers and the integration of particular transfer mechanisms, such as profit redistribution (as in the case of public enterprise) or direct governmental taxation. We may conjecture that the presence of substitute redistributive instruments should weaken the link established between equity and USOs. In particular, as a transfer targeted to unserved consumers reduces the marginal benefit of market coverage while the marginal cost of capacity remains the same at any location, we can expect that the optimal market coverage should not increase after the introduction of a supplementary transfer mechanism. However, given the increased complexity of the strategic interactions that this extension entails, this analysis is left for future research. 


\section{Appendix}

Hereafter, in order to simplify the presentation, we let $v_{d} \equiv v\left(p_{d}\right), v_{m} \equiv v\left(p_{m}\right), v_{s} \equiv v(\bar{p}(s))$, $r\left(p_{d}\right) \equiv r_{d}, r\left(p_{m}\right) \equiv r_{m}$ and $r(\bar{p}(s))=r_{s}$.

- Proof of Proposition 1. Since, one the one hand, the objective function is strictly increasing in $\theta_{m}$ and, on the other hand, $\tilde{\theta}_{m}$ is a feasible solution, we must have $\theta_{m}^{c} \geq \tilde{\theta}_{m}$, which proves the first inequality of the proposition. Assume that $\theta_{m}^{c}>\theta_{m}^{*}$. Then, from (6) and (7),

$$
\Pi\left(\tilde{\theta}_{d}, \theta_{m}^{c}\right) \leq \Pi\left(\tilde{\theta}_{d}, \theta_{m}^{*}\right)<\Pi\left(0, \theta_{m}^{*}\right)<0
$$

in contradiction with the constraint $\Pi\left(\tilde{\theta}_{d}, \theta_{m}^{c}\right) \geq 0$. We thus have $\theta_{m}^{c} \leq \theta_{m}^{*}$, which proves the second inequality of the proposition.

- Proof of Lemma 1. We provide here the FOCs for the problem (9). Let

$\mathcal{L}=F\left(\theta_{d}\right) \phi\left(v_{d}\right)+\left(F\left(\theta_{m}\right)-F\left(\theta_{d}\right)\right) \phi\left(v_{m}\right)+\left(1-F\left(\theta_{m}\right)\right) \phi(\epsilon)+\lambda \Pi\left(\theta_{d}, \theta_{m}\right)+\mu\left(1-\theta_{m}\right)+\gamma\left(\theta_{m}-\theta_{d}\right)$

be the Lagrangian, where $\lambda, \mu$ and $\gamma$ are Kuhn-Tucker multipliers. Then,

$$
\begin{aligned}
\mathcal{L}_{\theta_{m}}^{\prime} & =f\left(\theta_{m}\right)\left\{\phi\left(v_{m}\right)-\phi(\epsilon)+\lambda\left(r_{m}-k \theta_{m}\right)\right\}-\mu+\gamma \\
\mathcal{L}_{\theta_{d}}^{\prime} & =f\left(\theta_{d}\right)\left\{\phi\left(v_{d}\right)-\phi\left(v_{m}\right)+\lambda\left(r_{d}-r_{m}-k \theta_{d}\right)\right\}-\gamma
\end{aligned}
$$

and the FOCs are:

$$
\begin{array}{rllll}
\mathcal{L}_{\theta_{m}}^{\prime} \theta_{m}=0 & \mathcal{L}_{\theta_{m}}^{\prime} \leq 0 & \mu\left(1-\theta_{m}\right)=0 & 0 \leq \theta_{m} \leq 1, \mu \geq 0 \\
\mathcal{L}_{\theta_{d}}^{\prime} \theta_{d}=0 & \mathcal{L}_{\theta_{d}}^{\prime} \leq 0 & \gamma\left(\theta_{m}-\theta_{d}\right)=0 & 0 \leq \theta_{d} \leq \theta_{m}, \gamma \geq 0 \\
\mathcal{L}_{\lambda}^{\prime} \geq 0 & \mathcal{L}_{\lambda}^{\prime} \lambda=0 & \lambda \geq 0 . &
\end{array}
$$

In order to simplify the presentation, we let $\Delta(\rho) \equiv \frac{\phi\left(v_{d}\right)-\phi\left(v_{m}\right)}{\phi\left(v_{m}\right)-\phi(\epsilon)}$ and $\Gamma\left(\theta_{d}, \theta_{m}\right) \equiv \frac{k \theta_{d}+r_{m}-r_{d}}{k \theta_{m}-r_{m}} . \Delta(\cdot)$ represents the marginal rate of substitution of monopolistic coverage for duopolistic coverage, while $\Gamma(\cdot)$ represents the ratio of the marginal opportunity cost of duopolistic coverage to monopolistic coverage. We have:

$$
\Delta^{\prime}(\rho)=\frac{1}{v_{m}^{1-\rho}-\epsilon^{1-\rho}}\left(v_{d}^{1-\rho} v_{m}^{1-\rho} \ln \left(\frac{v_{d}}{v_{m}}\right)+\epsilon^{1-\rho}\left(v_{m}^{1-\rho} \ln \left(\frac{v_{m}}{\epsilon}\right)-v_{d}^{1-\rho} \ln \left(\frac{v_{d}}{\epsilon}\right)\right)\right) .
$$

Using L'Hôpital's rule for the last two terms, we obtain:

$$
\lim _{\epsilon \rightarrow 0} \Delta^{\prime}(\rho)=-\left(\frac{v_{d}}{v_{m}}\right)^{1-\rho} \ln \left(\frac{v_{d}}{v_{m}}\right)<0,
$$

since $v_{d}>v_{m}$. Thus, $\Delta(\rho)$ is decreasing with increased aversion to inequality $\rho$. 
We also have:

$$
\lim _{\rho \rightarrow 1^{-}} \lim _{\epsilon \rightarrow 0} \Delta(\rho)=\lim _{\rho \rightarrow 1^{-}} \frac{v_{d}^{1-\rho}-v_{m}^{1-\rho}}{v_{m}^{1-\rho}}=0 .
$$

We now consider in turn the cases that can occur with the FOCs using the preceding definitions. - Case 1: $\theta_{d}=\theta_{m}=1$ and $\lambda=0$. This is the case where duopolistic competition can be implemented in all locations as $\Pi(1,1) \geq 0$. This requires a sufficiently low capital cost $k$, i.e. $k \leq k_{(1)}=\frac{r_{d}}{2 H(1)}$. Perfect equity is reached independently of the regulator's aversion to equity because every consumer is covered at the same price. Uniform pricing is obtained even if it is not imposed formally.

- Case 2: $0 \leq \theta_{d}<\theta_{m} \leq 1$ and $\lambda=0$. Then $\gamma=0$. Substituting $\gamma=0$ and $\lambda=0$ in (A.2) shows that this case is impossible as $\mathcal{L}_{\theta_{d}}^{\prime}=f\left(\theta_{d}\right)\left\{\phi\left(v_{d}\right)-\phi\left(v_{m}\right)\right\}>0$, a contradiction.

- Case 3: $0 \leq \theta_{d}<\theta_{m}=1$ and $\lambda>0$. Then $\gamma=0$. From the binding profit constraint, we then have $\theta_{d}=\tau_{d}\left(p_{m}, p_{d}, k\right)$ where $\tau_{d}(\cdot)$ is implicitly defined by:

$$
F\left(\tau_{d}(\cdot)\right)\left(r_{m}-r_{d}\right)+k H\left(\tau_{d}(\cdot)\right)=r_{m}-k H(1)
$$

which implies that $k>k_{(1)}$ and $\tau_{d}>0$. Notice that if $k>k_{(0)}=\frac{r_{m}}{H(1)}>k_{(1)}$, then this case is unfeasible as the profit is negative for all $\theta_{d}$. With $\gamma=0$, (A.1) and (A.2) then imply that:

$$
\Delta(\rho) \leq \Gamma\left(\tau_{d}, 1\right)
$$

- Case 4: $\theta_{d}=0<\theta_{m}<1$ and $\lambda>0$. Then $\gamma=\mu=0$. We then obtain from the binding constraint that $\theta_{m}=\tau_{m}\left(p_{m}, k\right)$, where $\tau_{m}(\cdot)$ is implicitly defined by:

$$
F\left(\tau_{m}(\cdot)\right) r_{m}-k H\left(\tau_{m}(\cdot)\right)=0
$$

Invoking the mean theorem we can state $H\left(\theta_{m}\right) / F\left(\theta_{m}\right)<\theta_{m}$, so that $\tau_{m}>r_{m} / k$. Moreover substituting $\theta_{d}=0$ in (A.1) and (A.2) leads to:

$$
\Delta(\rho) \leq \Gamma\left(0, \tau_{m}\right)
$$

- Case 5: $0<\theta_{d}=\theta_{m}<1$ and $\lambda>0$. Then $\mu=0$. From the binding constraint, we then have $\theta_{d}=\theta_{m}=\tau\left(p_{d}, k\right)$ where $\tau(\cdot) \in\left(r_{m} / k, 1\right)$ is such that:

$$
F(\tau(\cdot)) r_{d} / 2=k H(\tau(\cdot))
$$

From (A.1) and (A.2) with $\theta_{d}=\theta_{m}=\tau$, we obtain:

$$
\Delta(\rho) \geq \Gamma(\tau, \tau)
$$


- Case 6: $0<\theta_{d}<\theta_{m}<1$ and $\lambda>0$. Then $\gamma=\mu=0$. Substituting these values in (A.1) and (A.2), we obtain:

$$
\lambda=\frac{\phi\left(v_{m}\right)-\phi(\epsilon)}{k \theta_{m}-r_{m}}=\frac{\phi\left(v_{d}\right)-\phi\left(v_{m}\right)}{k \theta_{d}+r_{m}-r_{d}}>0,
$$

which implies that $\theta_{m}>r_{m} / k$. This can be rewritten as:

$$
\Delta(\rho)=\Gamma\left(\theta_{d}, \theta_{m}\right)
$$

Hence, coverages $\left(\theta_{m}, \theta_{d}\right)$ are given by:

$$
\theta_{m}=\frac{\theta_{d}}{\Delta(\rho)}+\frac{(1+\Delta(\rho)) r_{m}-r_{d}}{k \Delta(\rho)}
$$

and

$$
F\left(\theta_{d}\right) r_{d}+\left(F\left(\theta_{m}\right)-F\left(\theta_{d}\right)\right) r_{m}=k\left(H\left(\theta_{d}\right)+H\left(\theta_{m}\right)\right)
$$

For this case to arise, we must have:

$$
\Gamma(\tau, \tau) \geq \Delta(\rho) \geq \max \left\{\Gamma\left(\tau_{d}, 1\right), \Gamma\left(0, \tau_{m}\right)\right\}
$$

If $\lambda>0, \rho=0$ and $\Delta(0) \geq \max \left\{\Gamma\left(\tau_{d}, 1\right), \Gamma\left(0, \tau_{m}\right)\right\}$, we are either in case 5 or in case 6 of the FOCs. If

$$
\Delta(0) \geq \Gamma(\tau, \tau)=\frac{k \tau+r_{m}-r_{d}}{k \tau-r_{m}}>1,
$$

then we are in case 5 at $\rho=0$. Since $\Delta^{\prime}<0$ and $\lim _{\rho \rightarrow 1^{-}} \lim _{\varepsilon \rightarrow 0} \Delta(\rho)=0$, there exists a $\rho \in[0, \underline{\rho}]$ where $\underline{\rho}$ is such that $\Delta(\underline{\rho})=\Gamma(\tau, \tau)$. Then case 5 prevails from $[0, \underline{\rho}]$. If $\Delta(0) \leq 1$, we necessarily have $\Delta(0)<\Gamma(\tau, \tau)$, so that we are in case 6 at $\rho=0$ and we set $\underline{\rho}=0$.

Since, under a binding profit constraint, $\tau_{d}<\tau<\tau_{m}$, we have:

$$
\begin{aligned}
& \Gamma(\tau, \tau)=\frac{k \tau+r_{m}-r_{d}}{k \tau-r_{m}} \geq \frac{k \tau_{d}+r_{m}}{k-r_{m}}=\Gamma\left(\tau_{d}, 1\right) \\
& \Gamma(\tau, \tau)=\frac{k \tau+r_{m}-r_{d}}{k \tau-r_{m}} \geq \frac{r_{m}-r_{d}}{k \tau_{m}-r_{m}}=\Gamma\left(0, \tau_{m}\right) .
\end{aligned}
$$

Then $\Gamma(\tau, \tau) \geq \Delta(\underline{\rho}) \geq \max \left\{\Gamma\left(\tau_{d}, 1\right), \Gamma\left(0, \tau_{m}\right)\right\}$, implying that case 6 prevails at $\rho=\underline{\rho}$.

Again, since $\Delta^{\prime}<0$ and $\lim _{\rho \rightarrow 1^{-}} \lim _{\varepsilon \rightarrow 0} \Delta(\rho)=0$, there exists a $\bar{\rho} \in(\underline{\rho}, \bar{\rho})$ such that $\Delta(\bar{\rho})=$ $\max \left\{\Gamma\left(\tau_{d}, 1\right), \Gamma\left(0, \tau_{m}\right)\right\}$. If $\Delta(\bar{\rho})=\Gamma\left(\tau_{d}, 1\right)$, then we have ubiquity with $\theta_{d}=\tau_{d}$ for all $\rho>\bar{\rho}$; if $\Delta(\bar{\rho})=\Gamma\left(0, \tau_{m}\right)$, we have $\theta_{m}=\tau_{m}$ and $\theta_{d}=0$ for all $\rho>\bar{\rho}$.

- Proof of Proposition 2. Consider case 6 of the FOCs. Then, the LHS of (A.6) is decreasing with increased aversion to inequality. By differentiating the RHS, we must then have:

$$
\frac{d \theta_{d}}{d \rho}\left[k \theta_{m}-r_{m}\right]<\left[k \theta_{d}-\left(r_{d}-r_{m}\right)\right] \frac{d \theta_{m}}{d \rho} .
$$


Now, the binding budget constraint implies that $\frac{d \theta_{d}}{d \rho}$ and $\frac{d \theta_{m}}{d \rho}$ have opposite signs, which can be shown by differentiating it:

$$
\begin{aligned}
-f\left(\theta_{d}\right)\left[k \theta_{d}-\left(r_{d}-r_{m}\right)\right] d \theta_{d} & =\left[k \theta_{m}-r_{m}\right] f\left(\theta_{m}\right) d \theta_{m} \\
& \Rightarrow \frac{d \theta_{d}}{d \theta_{m}}<0
\end{aligned}
$$

since $k \theta_{m}-r_{m}>0$ and $k \theta_{d}-\left(r_{d}-r_{m}\right)>0$ from (A.5). This implies that $\frac{d \theta_{m}}{d \rho}$ cannot be negative because it would contradict (A.8). Thus, we have $\frac{d \theta_{m}}{d \rho}>0$ and $\frac{d \theta_{d}}{d \rho}<0$ whenever the constraint is binding and the solution is such that $0<\theta_{d}<\theta_{m}<1$, i.e. whenever $\rho \in(\underline{\rho}, \bar{\rho})$. Considering the corner solutions where $\theta_{d}=0$ or $\theta_{m}=1$, i.e. whenever $\rho \geq \bar{\rho}$, we have $\frac{d \theta_{m}}{d \rho}=0$ and $\frac{d \theta_{d}}{d \rho}=0$. When the optimal solution is $\theta_{m}=\theta_{d}=\tau\left(p_{d}, k\right)$, i.e. whenever $\rho \in[0, \underline{\rho}]$, then $\frac{d \theta_{m}}{d \rho}=0$.

- Proof of Lemma 2. See Poudou and Roland [23], Lemma 2 for part (i) and Proposition 1 for part (ii).

- Proof of Lemma 3. Assuming that $s=\frac{F\left(\theta_{d}\right)}{F\left(\theta_{m}\right)}>0$, we have $v_{s}>v_{m}$ since $\bar{p}(s)<p_{m}$. Because the welfare function satisfies the independence of unconcerned agents, the fact that $\theta_{m}$ is fixed allows us to focus our attention on covered markets. The difference in the social welfare for covered markets in the case where UP is imposed and that where it is not imposed is given by:

$$
\Delta_{s}(\rho) \equiv v_{s}-\left[s v_{d}^{1-\rho}+(1-s) v_{m}^{1-\rho}\right]^{\frac{1}{1-\rho}}
$$

By convexity of $v(p)$ with respect to $p$, we have $v_{s} \leq s v_{d}+(1-s) v_{m}$, which implies that $\Delta_{s}(0) \leq 0$. However, the bracketed term is a weighted mean of order $1-\rho$ and, as shown by Mitronović [20], it is decreasing in $\rho$. Furthermore, the limit of the bracketed term as $\rho \rightarrow \infty$ is $v_{m}$. Thus, we have:

$$
\lim _{\rho \rightarrow \infty} \Delta_{s}(\rho)=v_{s}-v_{m}>0
$$

i.e., for a given $\left(\theta_{d}, \theta_{m}\right)$, there exists a $\rho$ over which welfare is greater under UP than that without it.

- Proof of Lemma 4. We have:

$$
s F\left(\theta_{m}\right) \bar{p}(s) \frac{D(\bar{p}(s))}{1+s}-k H\left(F^{-1}\left(s F\left(\theta_{m}\right)\right)\right)=F\left(\theta_{d}\right) \frac{r_{s}}{1+s}-k H\left(\theta_{d}\right) \geq F\left(\theta_{d}\right)\left(\frac{1}{2} r_{d}\right)-k H\left(\theta_{d}\right),
$$

since $r_{s} \geq r_{d}$ and $\frac{1}{1+s} \geq \frac{1}{2}$. In other words, for a fixed $\theta_{m}$, the entrant's marginal coverage revenue under UP is greater than or equal to its marginal coverage revenue without UP, whereas the marginal coverage cost is the same; therefore, the coverage cannot be lower under UP. If $\theta_{m}=\theta_{m}^{c}$ and $\theta_{d}=\tilde{\theta}_{d}$, then $s<1$, so that the inequality in (A.9) is strict and the entrant's coverage is strictly greater under UP. 
- Proof of Proposition 3. Let $\bar{\theta}_{m}$ represent the incumbent's coverage when it is subjected to UP without a CC, $\tilde{\theta}_{m}$ be the monopolistic coverage under UM, $\tilde{\theta}_{d}$ represent the duopolistic coverage under UM and $\tilde{s}=\frac{F\left(\tilde{\theta}_{d}\right)}{F\left(\tilde{\theta}_{m}\right)}$. Then the gain of imposing UP separately from the UM benchmark is:

$$
\begin{aligned}
\Delta_{U M}(\rho) & \equiv\left\{F\left(\bar{\theta}_{m}\right) v_{s}^{1-\rho}+\left(1-F\left(\bar{\theta}_{m}\right)\right) \epsilon^{1-\rho}\right\}^{\frac{1}{1-\rho}}-\left\{F\left(\tilde{\theta}_{m}\right)\left[\tilde{s} v_{d}^{1-\rho}+(1-\tilde{s}) v_{m}^{1-\rho}\right]+\left(1-F\left(\tilde{\theta}_{m}\right)\right) \epsilon^{1-\rho}\right\}^{\frac{1}{1-\rho}} \\
& <\left\{F\left(\tilde{\theta}_{m}\right) v_{s}^{1-\rho}+\left(1-F\left(\tilde{\theta}_{m}\right)\right) \epsilon^{1-\rho}\right\}^{\frac{1}{1-\rho}}-\left\{F\left(\tilde{\theta}_{m}\right)\left[\tilde{s} v_{d}^{1-\rho}+(1-\tilde{s}) v_{m}^{1-\rho}\right]+\left(1-F\left(\tilde{\theta}_{m}\right)\right) \epsilon^{1-\rho}\right\}^{\frac{1}{1-\rho}},
\end{aligned}
$$

where the inequality is due to the fact that $\bar{\theta}_{m}<\tilde{\theta}_{m}$, which comes from (4) and (16) with $s>0$. The limit of both terms in the last expression tends to $\epsilon$ as $\rho \rightarrow \infty$, so the last expression tends to 0 as $\rho \rightarrow \infty$. Thus, we have:

$$
\lim _{\rho \rightarrow \infty} \Delta_{U M}(\rho)<0 .
$$

As $\Delta_{U M}$ is continuous, there exists a $\bar{\rho}$ such that $\Delta_{U M}(\rho)<0$, for $\rho \in[\bar{\rho}, \infty[$, i.e., a $\bar{\rho}$ over which UM is socially preferred to UP. However, note that we cannot exclude the case of a non-monotonic shape of $\Delta_{U M}(\rho)$ for $0 \leq \rho \leq \bar{\rho}$ and the case that $\bar{\rho}=0$ so UM would be always socially preferred to UP.

- Proof of Proposition 4. Let $\bar{\theta}_{m}$ represent the incumbent's coverage when it is subjected to UP. Comparing (4) and (16) with $s>0$ and invoking Proposition 1 , we have $\bar{\theta}_{m}<\tilde{\theta}_{m} \leq \theta_{m}^{c}$. Noting that the entrant's coverage under CC is $\tilde{\theta}_{d}$, we let $s^{c} \equiv \frac{F\left(\tilde{\theta}_{d}\right)}{F\left(\theta_{m}^{c}\right)}$ be the share of duopolistic markets under CC. By a similar reasoning to that in the proof of Proposition 3, we obtain:

$$
\begin{aligned}
\Delta_{C}(\rho) & \equiv\left\{F\left(\bar{\theta}_{m}\right) v_{s}^{1-\rho}+\left(1-F\left(\bar{\theta}_{m}\right)\right) \epsilon^{1-\rho}\right\}^{\frac{1}{1-\rho}}-\left\{F\left(\theta_{m}^{c}\right)\left[s^{c} v_{d}^{1-\rho}+\left(1-s^{c}\right) v_{m}^{1-\rho}\right]+\left(1-F\left(\theta_{m}^{c}\right)\right) \epsilon^{1-\rho}\right\}^{\frac{1}{1-\rho}} \\
& <\left\{F\left(\theta_{m}^{c}\right) v_{s}^{1-\rho}+\left(1-F\left(\theta_{m}^{c}\right)\right) \epsilon^{1-\rho}\right\}^{\frac{1}{1-\rho}}-\left\{F\left(\theta_{m}^{c}\right)\left[s^{c} v_{d}^{1-\rho}+\left(1-s^{c}\right) v_{m}^{1-\rho}\right]+\left(1-F\left(\theta_{m}^{c}\right)\right) \epsilon^{1-\rho}\right\}^{\frac{1}{1-\rho}}
\end{aligned}
$$

so that $\lim _{\rho \rightarrow \infty} \Delta_{C}(\rho)<0$. This implies that there exists a $\rho$ over which CC is socially preferred to UP. As CC+LC weakly dominates CC in terms of welfare, it follows that there also exists a $\rho$ over which $\mathrm{CC}+\mathrm{LC}$ is socially preferred to UP.

- Proof of Proposition 5. It suffices to replace $\bar{\theta}_{m}$ by the CC+UP coverage in the proof of Proposition 4.

- Proof of Proposition 6. (i) This follows from the fact that a feasible solution under CC+UP is feasible under CC+LC+UP. (ii) This follows directly from part (ii) of Lemma 2 and from Lemma 3.

- Proof of Proposition 7. We check in turn the validity of each proposition when constraints (19) and (20) replace the industry profit constraint in the various problems considered. 
(i) Proposition 2. In order to show that Proposition 2 holds, consider the $\mathrm{CC}+\mathrm{LC}$ case with these constraints. The problem is:

$$
\begin{array}{cl}
\max _{\theta_{m}, \theta_{d}} & F\left(\theta_{d}\right) \phi\left(v_{d}\right)+\left(F\left(\theta_{m}\right)-F\left(\theta_{d}\right)\right) \phi\left(v_{m}\right)+\left(1-F\left(\theta_{m}\right)\right) \phi(\epsilon) \\
\text { s.t. } & \\
& \Pi_{I}\left(\theta_{d}, \theta_{m}\right)+\delta\left(\Pi_{E}\left(\theta_{d}\right)-\Pi_{E}^{0}\right) \geq \Pi_{I}^{0} \\
& \Pi_{E}\left(\theta_{d}\right)+\delta\left(\Pi_{I}\left(\theta_{d}, \theta_{m}\right)-\Pi_{I}^{0}\right) \geq \Pi_{E}^{0},
\end{array}
$$

where:

$$
\begin{aligned}
\Pi_{I}\left(\theta_{d}, \theta_{m}\right) & =\frac{1}{2} F\left(\theta_{d}\right) r_{d}+\left[F\left(\theta_{m}\right)-F\left(\theta_{d}\right)\right] r_{m}-k H\left(\theta_{m}\right) \\
\Pi_{E}\left(\theta_{d}\right) & =\frac{1}{2} F\left(\theta_{d}\right) r_{d}-k H\left(\theta_{d}\right) .
\end{aligned}
$$

Let

$$
\begin{aligned}
\mathcal{L}\left(\theta_{m}, \theta_{d}, \lambda_{I}, \lambda_{E}\right)= & F\left(\theta_{d}\right) \phi\left(v_{d}\right)+\left(F\left(\theta_{m}\right)-F\left(\theta_{d}\right)\right) \phi\left(v_{m}\right)+\left(1-F\left(\theta_{m}\right)\right) \phi(\epsilon) \\
& +\lambda_{I}\left[\left(\Pi_{I}\left(\theta_{d}, \theta_{m}\right)-\Pi_{I}^{0}\right)+\delta\left(\Pi_{E}\left(\theta_{d}\right)-\Pi_{E}^{0}\right)\right]+\lambda_{E}\left[\left(\Pi_{E}\left(\theta_{d}\right)-\Pi_{E}^{0}\right)+\delta\left(\Pi_{I}\left(\theta_{d}, \theta_{m}\right)-\Pi_{I}^{0}\right)\right] \\
& +\mu\left(1-\theta_{m}\right)+\gamma\left(\theta_{m}-\theta_{d}\right)
\end{aligned}
$$

be the Lagrangian. Then, we have:

$$
\begin{aligned}
\mathcal{L}_{\theta_{m}}^{\prime}= & f\left(\theta_{m}\right)\left\{\phi\left(v_{m}\right)-\phi(\epsilon)+\left(\lambda_{I}+\delta \lambda_{E}\right)\left(r_{m}-k \theta_{m}\right)\right\}-\mu+\gamma \\
\mathcal{L}_{\theta_{d}}^{\prime}= & f\left(\theta_{d}\right)\left\{\phi\left(v_{d}\right)-\phi\left(v_{m}\right)+\lambda_{I}\left[\frac{1}{2}(1+\delta) r_{d}-r_{m}-\delta k \theta_{d}\right]\right. \\
& \left.+\lambda_{E}\left[\frac{1}{2}(1+\delta) r_{d}-k \theta_{d}-\delta r_{m}\right]\right\}-\gamma .
\end{aligned}
$$

Assume that both constraints are binding. Then, we have:

$$
\Pi_{I}\left(\theta_{d}, \theta_{m}\right)-\Pi_{I}^{0}=\delta\left(\Pi_{E}\left(\theta_{d}\right)-\Pi_{E}^{0}\right)=\delta^{2}\left(\Pi_{I}\left(\theta_{d}, \theta_{m}\right)-\Pi_{I}^{0}\right),
$$

which can arise only when $\Pi_{I}-\Pi_{I}^{0}=\Pi_{E}-\Pi_{E}^{0}=0$ or when $\delta=1$, in which case one constraint is redundant. For $\delta \in(0,1)$ and $\Pi_{I} \neq \Pi_{I}^{0}$ or $\Pi_{E} \neq \Pi_{E}^{0}$, one of the constraints is necessarily slack, so one of the multipliers is equal to zero. We consider each case in turn.

- Case 1: $\lambda_{E}=0$. Consider an interior solution where $0<\theta_{d}<\theta_{m}<1$. Then, it follows from (A.12) and (A.13) that:

$$
\lambda_{I}=\frac{\phi\left(v_{m}\right)-\phi(\epsilon)}{k \theta_{m}-r_{m}}=\frac{\phi\left(v_{d}\right)-\phi\left(v_{m}\right)}{\delta k \theta_{d}-\left(\frac{1}{2}(1+\delta) r_{d}-r_{m}\right)},
$$


which implies that:

$$
\frac{\phi\left(v_{d}\right)-\phi\left(v_{m}\right)}{\phi\left(v_{m}\right)-\phi(\epsilon)}=\frac{\delta k \theta_{d}-\left(\frac{1}{2}(1+\delta) r_{d}-r_{m}\right)}{\left(k \theta_{m}-r_{m}\right)} .
$$

Compared to (A.6), we have the same LHS, so $\lim _{\epsilon \rightarrow 0} \frac{d \Delta}{\delta \rho}<0$, where $\Delta \equiv \frac{\phi\left(v_{d}\right)-\phi\left(v_{m}\right)}{\phi\left(v_{m}\right)-\phi(\epsilon)}$. By differentiating the RHS, we must then have:

$$
\frac{d \theta_{d}}{d \rho}\left[k \theta_{m}-r_{m}\right]<\delta\left[\delta k \theta_{d}-\left(\frac{1}{2}(1+\delta) r_{d}-r_{m}\right)\right] \frac{d \theta_{m}}{d \rho} .
$$

Now, constraint (19) implies that $\frac{d \theta_{d}}{d \rho}$ and $\frac{d \theta_{m}}{d \rho}$ have opposite signs, which can be shown by differentiating it:

$$
\begin{aligned}
-f\left(\theta_{d}\right)\left[\delta k \theta_{d}-\left(\frac{1}{2}(1+\delta) r_{d}-r_{m}\right)\right] d \theta_{d} & =\left[k \theta_{m}-r_{m}\right] f\left(\theta_{m}\right) d \theta_{m} \\
& \Rightarrow \frac{d \theta_{d}}{d \theta_{m}}<0
\end{aligned}
$$

since $k \theta_{m}-r_{m}>0$ and $\delta k \theta_{d}-\left(\frac{1}{2}(1+\delta) r_{d}-r_{m}\right)>0$ from (A.14). This implies that $\frac{d \theta_{m}}{d \rho}$ cannot be negative because it would contradict (A.16). Thus, we have $\frac{d \theta_{m}}{d \rho}>0$ and $\frac{d \theta_{d}}{d \rho}<0$ whenever the solution is such that $0<\theta_{d}<\theta_{m}<1$. Considering the corner solutions where $\theta_{d}=0$ or $\theta_{m}=1$, we have $\frac{d \theta_{m}}{d \rho}=0$ and $\frac{d \theta_{d}}{d \rho}=0$. When the optimal solution is $0<\theta_{d}=\theta_{m}<1$, then coverage is the value $\tau$ such that $\frac{F(\tau) r_{d}}{2}=k H(\tau)+\frac{\Pi_{I}^{0}+\delta \Pi_{E}^{0}}{1+\delta}$, so that $\frac{d \theta_{m}}{d \rho}=0$.

- Case 2: $\lambda_{I}=0$.

Consider an interior solution where $0<\theta_{d}<\theta_{m}<1$. Then, it follows from (A.12) and (A.13) that:

$$
\lambda_{E}=\frac{1}{\delta} \frac{\phi\left(v_{m}\right)-\phi(\epsilon)}{k \theta_{m}-r_{m}}=\frac{\phi\left(v_{d}\right)-\phi\left(v_{m}\right)}{k \theta_{d}-\left(\frac{1}{2}(1+\delta) r_{d}-r_{m}\right)},
$$

which implies that:

$$
\frac{\phi\left(v_{d}\right)-\phi\left(v_{m}\right)}{\phi\left(v_{m}\right)-\phi(\epsilon)}=\frac{k \theta_{d}-\left(\frac{1}{2}(1+\delta) r_{d}-r_{m}\right)}{\delta\left(k \theta_{m}-r_{m}\right)} .
$$

The argument then follows the same lines as in Case 1 and we obtain $\frac{d \theta_{m}}{d \rho}>0$ and $\frac{d \theta_{d}}{d \rho}<0$ when the solution is such that $0<\theta_{d}<\theta_{m}<1$. Considering the corner solutions where $\theta_{d}=0$ or $\theta_{m}=1$, we have $\frac{d \theta_{m}}{d \rho}=0$ and $\frac{d \theta_{d}}{d \rho}=0$. When the optimal solution is $0<\theta_{d}=\theta_{m}<1$, then coverage is the value $\tau$ such that $\frac{F(\tau) r_{d}}{2}=k H(\tau)+\frac{\Pi_{E}^{0}+\delta \Pi_{I}^{0}}{1+\delta}$, so that $\frac{d \theta_{m}}{d \rho}=0$.

Thus, we find that Proposition 2 holds for $0 \leq \delta \leq 1$.

(ii) Proposition 3. The firms' choices are still given by $\left(\bar{\theta}_{d}, \bar{\theta}_{m}\right)$ under UP and by $\left(\tilde{\theta}_{d}, \tilde{\theta}_{m}\right)$ under UM. It is however possible that transfers cannot be made under UP to meet constraints (19) and 
(20), in which case UP cannot be implemented and consumers are not served $(V(\theta)=0, \forall \theta)$. In such a case, UM brings higher social welfare whatever is $\rho$. If UP can be implemented, we revert to the solution considered in the proof of Proposition 3. So there is always a $\rho$ over which social welfare is greater under UM than under UP and Proposition 3 is still verified.

(iii) Proposition 4. This follows from Proposition 3 and the fact that UM coverages $\left(\tilde{\theta}_{d}, \tilde{\theta}_{m}\right)$ are feasible under CC+LC with constraints (19) and (20), so that social welfare under CC+LC is never lower than social welfare under UM.

(iv) Proposition 5. As it is still possible that the incumbent's coverage under CC+UP be lower than the incumbent's coverage under CC with constraints (19) and (20), this proposition follows through.

(v) Proposition 6. ( $i$ ) If $\mathrm{CC}+\mathrm{UP}$ is feasible, then $\mathrm{CC}+\mathrm{LC}+\mathrm{UP}$ is feasible and the result holds. ( $i i$ ) Let $\Pi_{i}^{U}\left(\theta_{d}, \theta_{m}\right)$ and $\Pi_{i}\left(\theta_{d}, \theta_{m}\right)$ be firm's $i$ profit with coverages $\left(\theta_{d}, \theta_{m}\right)$ under UP and without UP, respectively, and let $\left(\hat{\theta}_{d}, \hat{\theta}_{m}\right)$ be optimal coverages under $\mathrm{CC}+\mathrm{LC}$ with constraints (19) and (20). From Lemma $2(i i)$, we have that:

$$
\Delta \Pi=\left[\Pi_{E}^{U}\left(\hat{\theta}_{d}, \hat{\theta}_{m}\right)-\Pi_{E}\left(\hat{\theta}_{d}, \hat{\theta}_{m}\right)\right]+\left[\Pi_{I}^{U}\left(\hat{\theta}_{d}, \hat{\theta}_{m}\right)-\Pi_{I}\left(\hat{\theta}_{d}, \hat{\theta}_{m}\right)\right]>0,
$$

where $\Pi_{E}^{U}\left(\hat{\theta}_{d}, \hat{\theta}_{m}\right)-\Pi_{E}\left(\hat{\theta}_{d}, \hat{\theta}_{m}\right) \geq 0$ since $\bar{p}(s) \geq p_{d}$. If this entrant's gain can compensate an eventual incumbent's loss, then the $\mathrm{CC}+\mathrm{LC}$ coverages remain feasible under $\mathrm{CC}+\mathrm{LC}+\mathrm{UP}$. Such a compensation can be made if:

$$
\delta \geq \delta^{0}=\frac{\Pi_{I}\left(\hat{\theta}_{d}, \hat{\theta}_{m}\right)-\Pi_{I}^{U}\left(\hat{\theta}_{d}, \hat{\theta}_{m}\right)}{\Pi_{E}^{U}\left(\hat{\theta}_{d}, \hat{\theta}_{m}\right)-\Pi_{E}\left(\hat{\theta}_{d}, \hat{\theta}_{m}\right)} .
$$

Thus, if $\delta \geq \delta^{0}$, there exists a $\rho$ over which $\mathrm{CC}+\mathrm{LC}+\mathrm{UP}$ brings higher social welfare than $\mathrm{CC}+\mathrm{LC}$.

\section{References}

[1] Aguirre, I., Cowan, S. and J. Vickers (2010), "Monopoly Price Discrimination and Demand Curvature", American Economic Review, 100, 1601-1615.

[2] Anderson, S. P., and R. Renault, "Efficiency and Surplus Bounds in Cournot Competition", Journal of Economic Theory, 113 (2003), 253-264.

[3] Anton, J., Vander Weide, J. H. and N. Vettas (2002), "Entry Auctions and Strategic Behaviour under Cross-Market Price Constraints", International Journal of Industrial Organization, 20, 611-629. 
[4] Atkinson, A. B., "On the Measurement of Inequality", Journal of Economic Theory, 2 (1970), 244-263.

[5] Bourguignon, H. and J. A. Ferrando (2007), "Skimming the Others' Cream: Competitive Effects of an Asymmetric Universal Service Obligation", International Journal of Industrial Organization, 25, 761-790.

[6] Calzada, J. (2009), "Universal Service Obligations in the Postal Sector: The Relationship between Quality and Coverage", Information Economics and Policy, 21, 10-20.

[7] Chen, Y. and M. Schwarz, "Differential Pricing when Costs Differ: A Welfare Analysis", Rand Journal of Economics, 46 (2015), 442-460.

[8] Choné, P., Flochel, L. and A. Perrot (2000), "Universal Service Obligations and Competition", Information Economics and Policy, 12, 249-259.

[9] Choné, P., Flochel, L. and A. Perrot (2002), "Allocating and Funding Universal Service Obligations in a Competitive Market", International Journal of Industrial Organization, 20, 12471276 .

[10] Cremer, H., De Donder P., Bodron F., D. Joram and B. Roy (2008), "Social Costs and Benefits of the Universal Service Obligation in the Postal Market", in Competition and Regulation in the Postal and Delivery Sector, Edward Elgar Publishing, 23-35.

[11] Cremer, H., Gasmi, F., Grimaud, A. and J.-J. Laffont (1998), "The Economics of Universal Service: Theory", The Economic Development Institute of the World Bank.

[12] Crew, M. A. and P. R. Kleindorfer (1998), "Efficient Entry, Monopoly and the Universal Service Obligation in Postal Service", Journal of Regulatory Economics, 14, 103-125.

[13] Foros, O. and H. J. Kind (2003), "The Broadband Access Market: Competition, Uniform Pricing and Geographical Coverage", Journal of Regulatory Economics, 23, 215-235.

[14] Gautier, A. and K. Minuzo (2011), "Gradual Network Expansion and Universal Service Obligations", Annals of Public and Cooperative Economics, 82, 97-113.

[15] Gautier, A. and D. Paolini (2011), "Universal Service Financing in Competitive Postal Markets: One Size Does Not Fit All", Review of Network Economics, 10, 1-28.

[16] Gautier, A. and X. Wauthy (2010), "Price Competition under Universal Service Obligations", International Journal of Economic Theory, 6, 311-326. 
[17] Gautier, A. and X. Wauthy (2012), "Competitively Neutral Universal Service Obligations", Information Economics and Policy, 24, 254-261.

[18] Jaag, C. (2011), "What is an Unfair Burden? Compensating the Net Cost of Universal Service Provision", Review of Network Economics, 10, Issue 3, Article 7.

[19] Jorge, S. F. and C. P. Pires, "Does Banning Price Discrimination Promote Entry and Increase Welfare? A Model of Differentiated-Product Duopoly with Asymetric Markets", The Manchester School, 81 (2013), 660-681.

[20] Mitronović, D. S., Analytic Inequalities, Springer-Verlag, 1970.

[21] Moulin, H. J., Fair Division and Collective Welfare, MIT Press, 2003.

[22] Oxera Consulting Limited (2007) "Funding Universal Service Obligations in the Postal Sector", http://www.oxera.com/ .

[23] Poudou, J.-C. and M. Roland, "Efficiency of Uniform Pricing in Universal Service Obligations", International Journal of Industrial Organization, 37 (2014), 141-152.

[24] Valletti, T., Hoernig S. and P. Barros (2002), "Universal Service and Entry: The Role of Uniform Pricing and Coverage Constraints", Journal of Regulatory Economics, 21, 169-190. 